
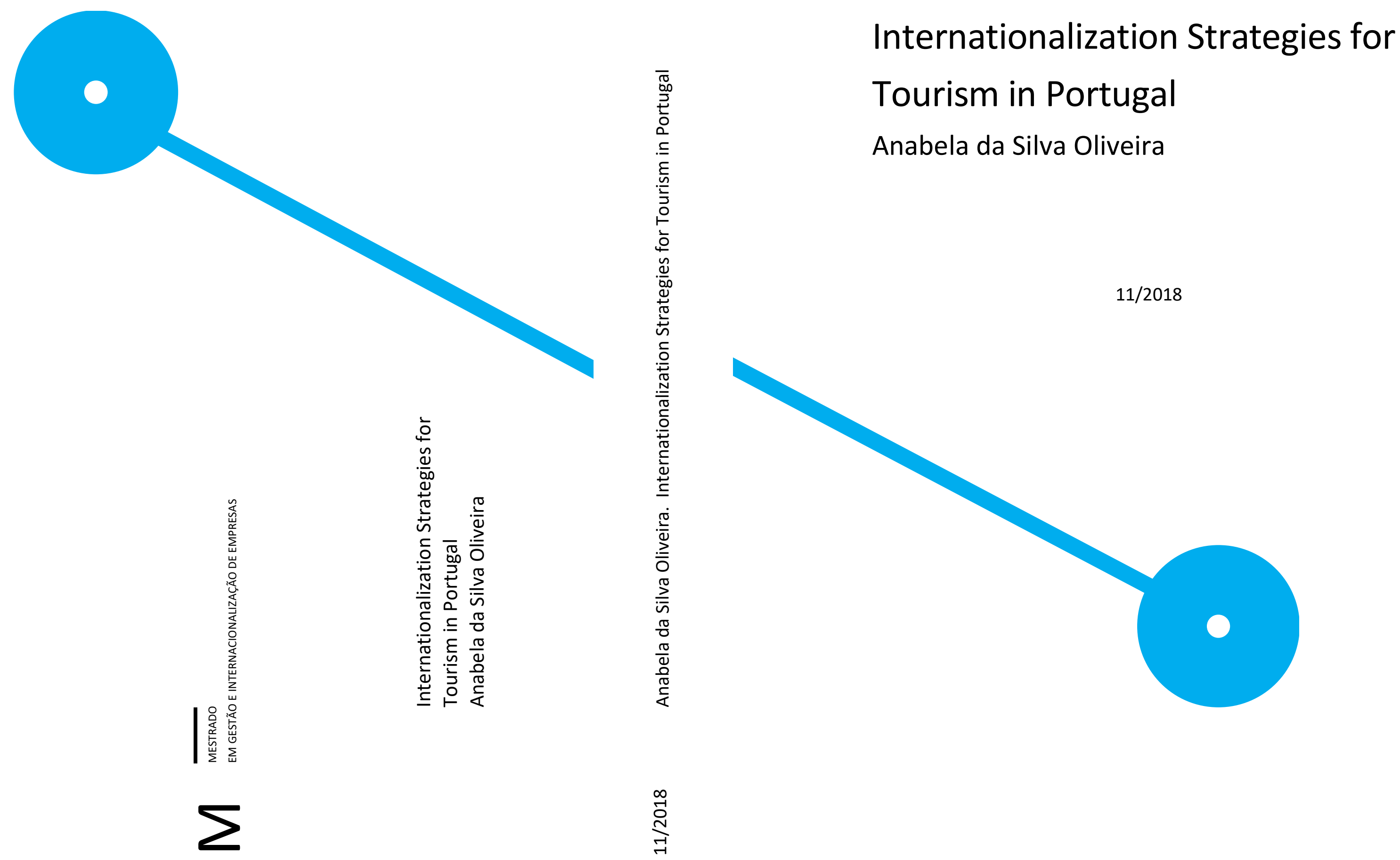


\section{Internationalization Strategies for Tourism in Portugal}

Anabela da Silva Oliveira

Prof. Vítor Braga

Prof. Eliana Costa e Silva 


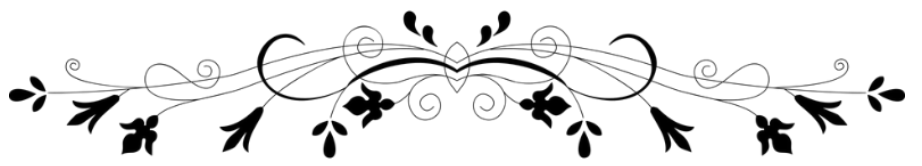

"Education is the most powerful weapon which you can use to change the world."

- Nelson Mandela

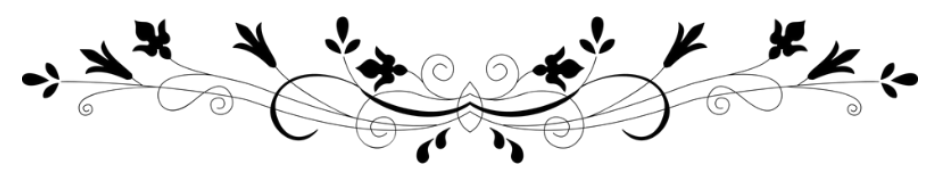




\section{Acknowledgements}

The present dissertation is testimony that sometimes the choice of a difficult path can be more enriching and that all the effort will be rewarded by the accomplishment of the defined objectives, reason why it is necessary to express the sincere thanks and gratitude inherent in this process.

Firstly, I would like to thank my mentors, Professor Vítor Braga and Professor Eliana Costa e Silva, for all the guidance, constructive criticism, dedication and effort, applied in the various moments to accomplish objectives, deadlines and dynamize this dissertation in a more correct and comprehensive way. A special recognition for all the hours spent in search of results, studies and sharing of knowledge, as well as for all the commitment made with me to the realization of it.

Next, I would like to thank the Escola Superior de Tecnologia e Gestão, responsible for my training throughout the academic course and the Research Centre, for the availability of tools and opportunity to participate in events that allowed the dissemination of this work.

To my parents, thank you for your work over the years, for always believed in me, for the affection and for making available all the resources so that nothing was lacking in me at educational level, and at all other levels, encouraging me every day and putting hope in every conquest or obstacle.

To Pedro, I would like to thank you for your fellowship and your patience throughout this academic journey. For the support, love and for being tireless to motivate me, to never give up my goals and to collaborate with me in any situation, keeping the worries away.

Also, a special thanks to Vera, who even with the rush of everyday life, made available to support me in the realization of this dissertation.

Thanks to all the wonderful people who have been with me during this academic journey, this experience has become even more significant and rewarding on a personal and professional level, and without a doubt it will be on your side that another victory will be celebrated.

To all I express my sincere gratitude. 


\section{List of Contents}

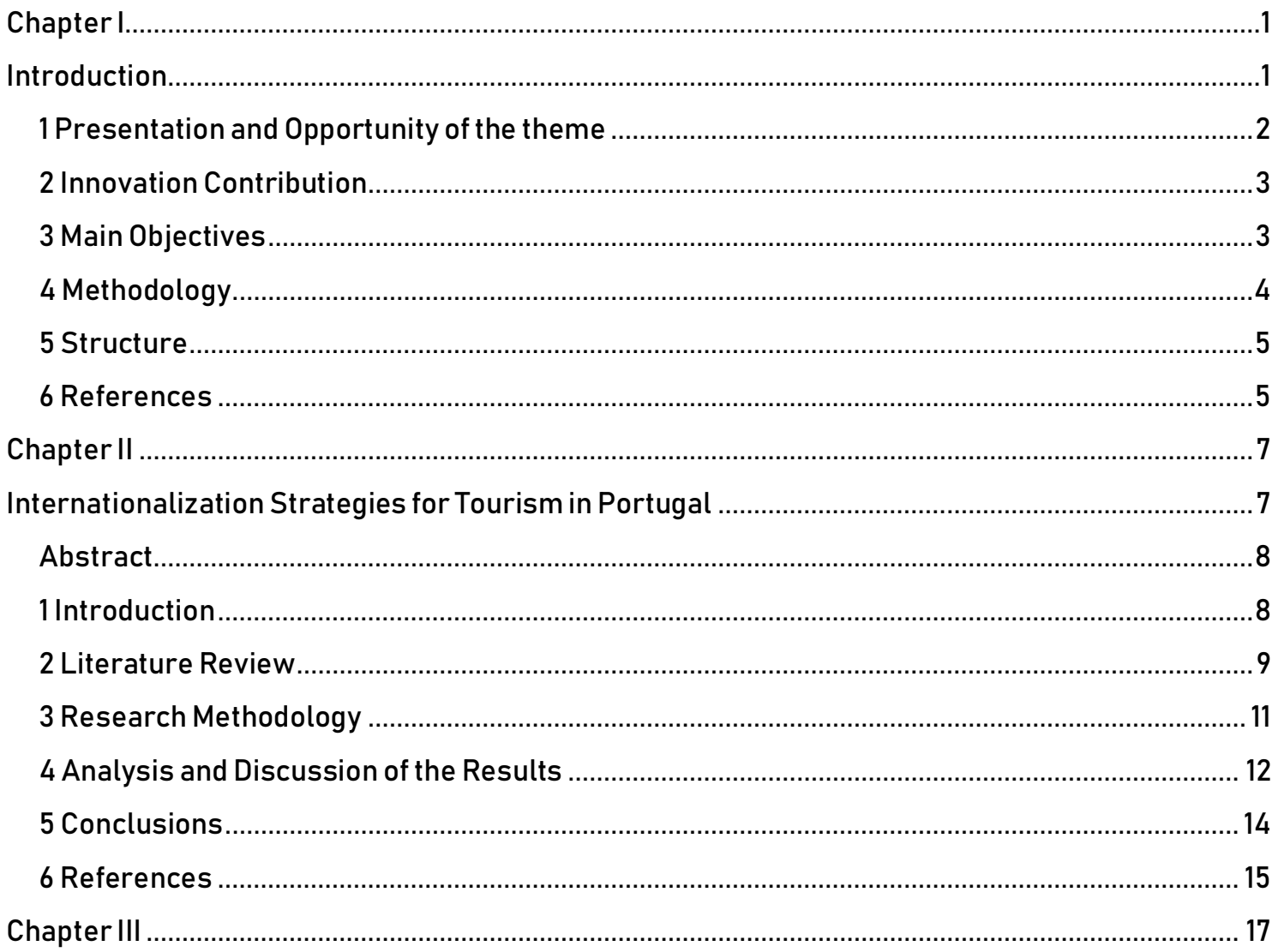

Internationalization Innovative Strategies for Tourism in Portugal: Municipal Analysis and

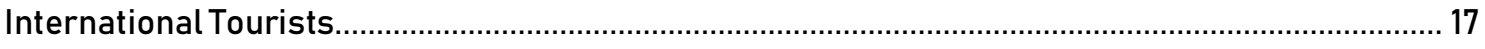

Abstract

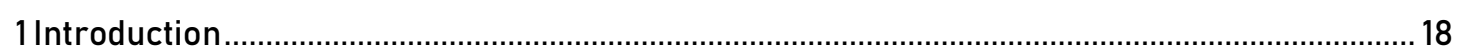

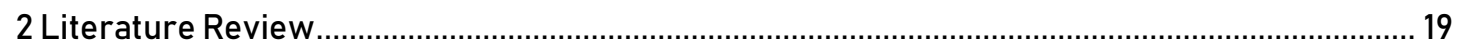

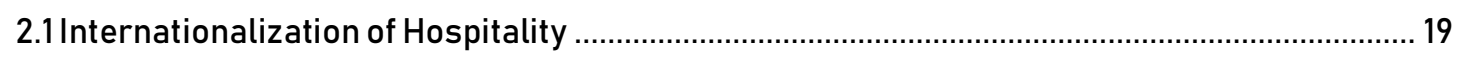

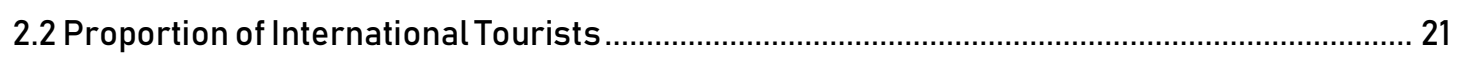

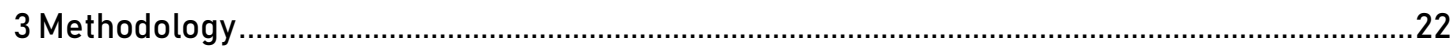

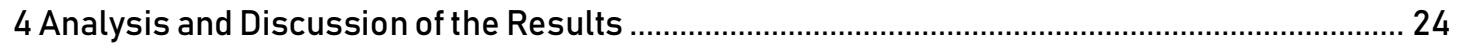

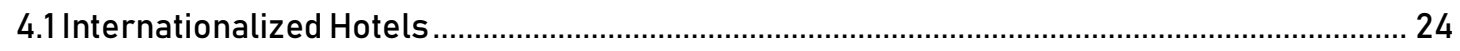

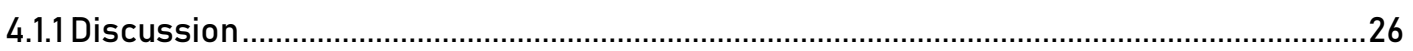

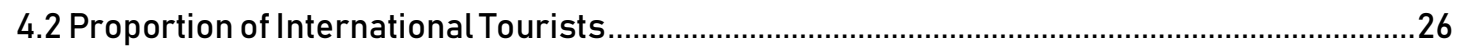

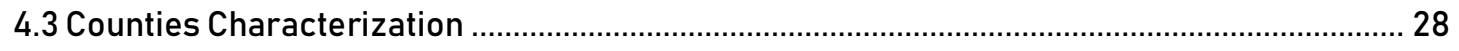

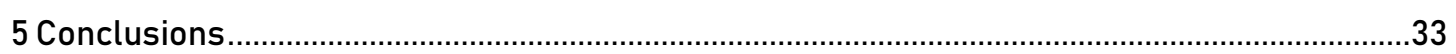

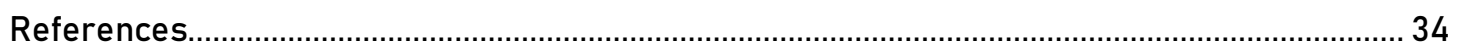

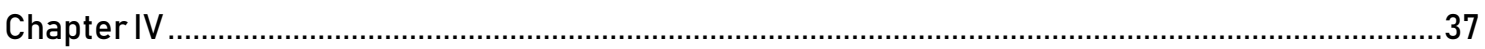

When Hotels go Abroad: The Internationalisation of the Portuguese Hospitality................................37

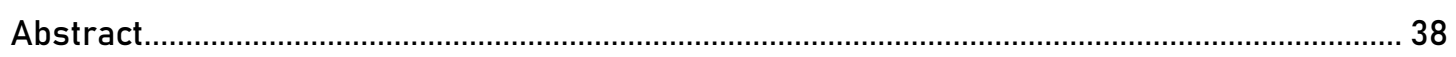

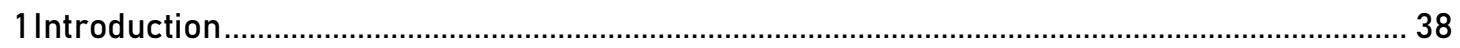




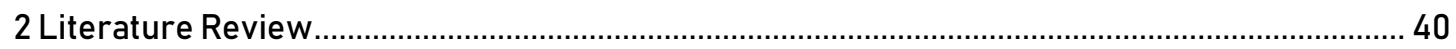

2.1 Internationalisation of Hotels in Tourism Sector.............................................................. 40

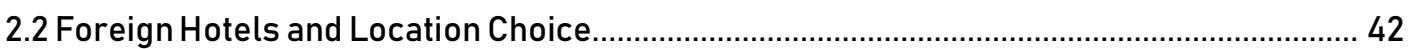

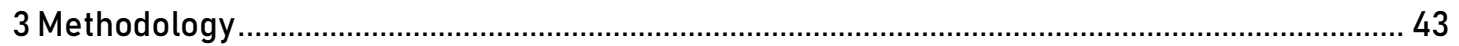

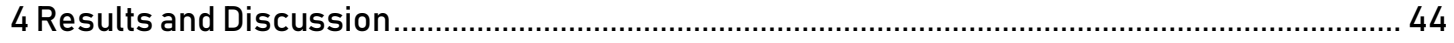

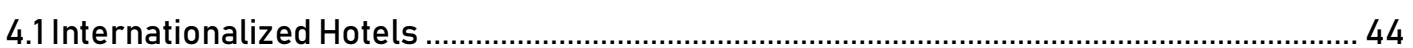

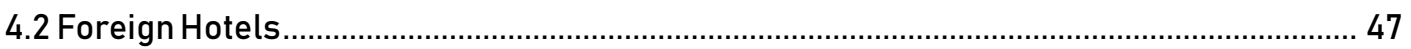

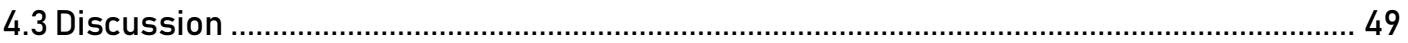

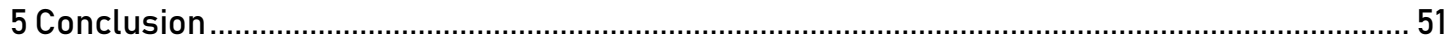

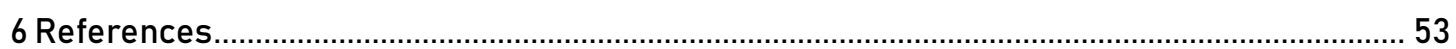

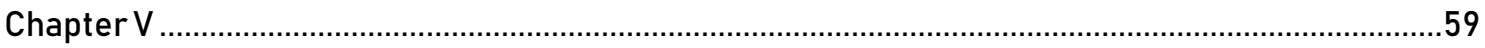

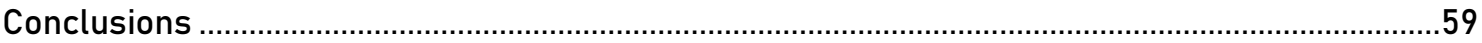

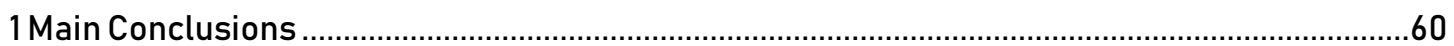

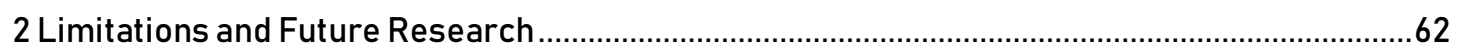

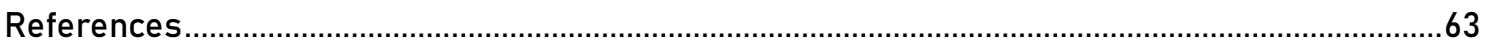




\section{List of Tables}

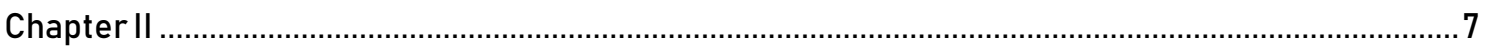

Internationalization Strategies for Tourism in Portugal ............................................................

Table 1. Spearman Correlation (non-parametric test) with the dependent variable HOT_Int...... 13

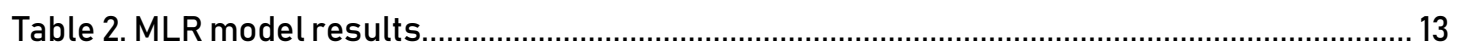

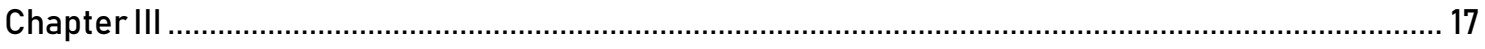

Internationalization Innovative Strategies for Tourism in Portugal: Municipal Analysis and

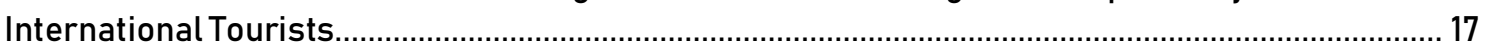

Table 1. Minimum, maximum, median, mean, standard deviation, skewness and kurtosis for the dependent variable HOT_Int ..................................................................................................... 24

Table 2. Pearson and Spearman Correlation with the dependent variable HOT_Int .....................25

Table 3. MLR model results for the dependent variable HOT_Int................................................25

Table 4. Minimum, maximum, median, mean, standard deviation, skewness and kurtosis for the

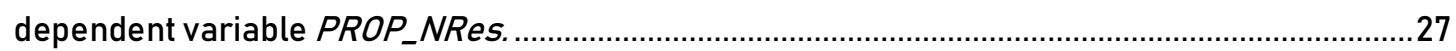

Table 5. Pearson and Spearman Correlation with the dependent variable PROP_NRes..............27

Table 6. MLR model results for the dependent variable PROP_NRes.......................................... 28

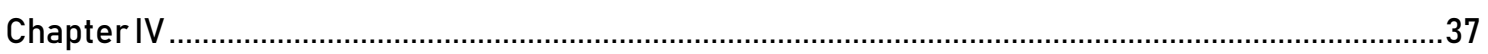

When Hotels go Abroad: The Internationalisation of the Portuguese Hospitality..............................37

Table 1. Median, mean, standard deviation and Mann-Whitney-Wilcoxon test for two groups

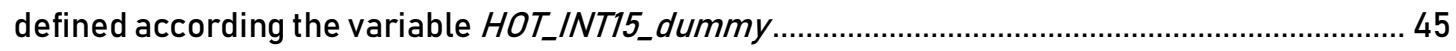

Table 2. Summary of logit model in Equation 1.......................................................................... 46

Table 3. Median, mean, standard deviation and Mann-Whitney-Wilcoxon test for two groups

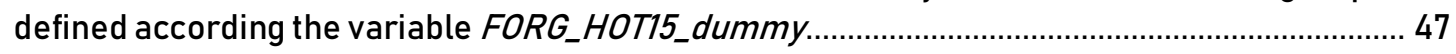

Table 4. Summary of logit model in Equation 2 ……………................................................... 48 


\section{List of Figures}

Chapter III

Internationalization Innovative Strategies for Tourism in Portugal: Municipal Analysis and

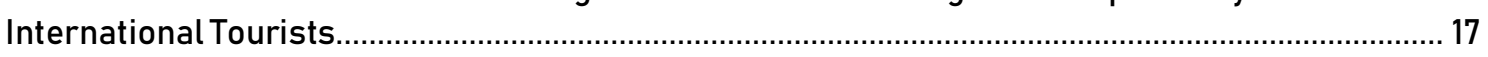

Figure 1. Internationalized hotels relativized by 100.000 inhabitants ........................................29

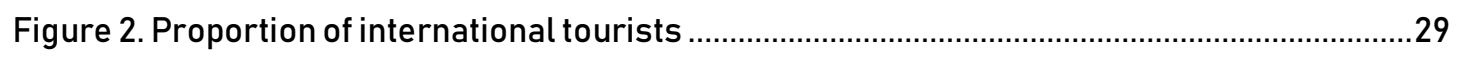

Figure 3. Degree of agglomeration of firms in the tourism sector ............................................ 30

Figure 4. University institutions relativized by 100.000 inhabitants ........................................... 30

Figure 5. Professional institutions relativized by 100.000 inhabitants.......................................... 31

Figure 6. R\&D centres - public/private ................................................................................ 31

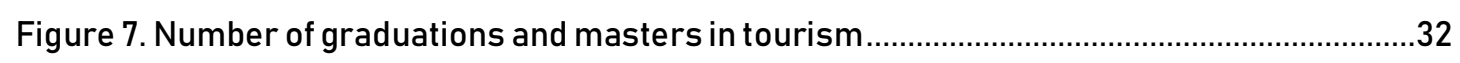

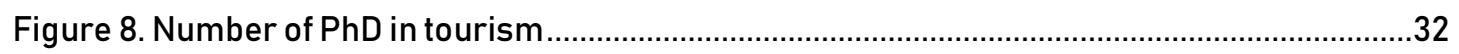

Figure 9. Number of professional courses in tourism ...............................................................3

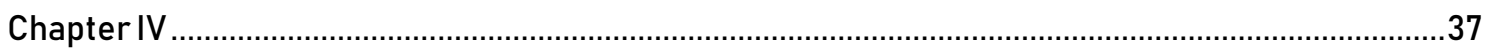

When Hotels go Abroad: The Internationalisation of the Portuguese Hospitality.............................37

Figure 1. Fitted values and index vs. residual deviance ................................................................ 47

Figure 2. Fitted values and index vs. residual deviance ........................................................... 49 


\section{List of Acronyms}

MLR - Multivariate Linear Regression

TU - Territorial Units

NUTS - Nomenclature of Territorial Units for Statistical Purposes

SMEs - Small and Medium Enterprises

SPSS - Statistical Package for the Social Sciences

INE - Instituto Nacional de Estatística

TP - Turismo de Portugal

R\&D - Research \& Development

DW - Durbin-Watson

FDI - Foreign Direct Investment 


\section{Abstract}

The acquisition of free movement of people and commerce and the reduction of economic, political and social barriers, tourism has shown to be a mechanism of wealth generation. However, the constant changes in the economic space and the saturation of the internal market led the tourism sector to become more competitive and apply innovation and differentiation in its products / services.

In order to survive in the market and maintain its competitive position, the hotel industry found in its internal advantages an opportunity to explore international markets, so over the years the internationalization of tourism and its potential impact on regional economic and social development, as well as their determinants, have been intensified by scholars.

Despite the high contribution of this industry to the development of the economy, many inequalities persist in terms of the tourist flow, internationalization or establishment of foreign hotel chains proportional in all Portuguese regions. In this sense, the literature lists some variables that may explain this phenomenon, such as educational level, shared knowledge and experiences acquired by human resources; the degree of agglomeration of tourism firms and complementary products; macroeconomic factors underlying the economy or even inherited / acquired resources or climacteric factors.

In order to find out the impact of the determinants in the hotel industry and tourism flows, three different studies were conducted, one being established at the level of NUTS III and the rest at the counties level, allowing to compare results.

At an initial stage, in order to verify statistical evidence to confirm that the variables validated by the literature, i.e. agglomeration, knowledge and touristic resources, are significant for the internationalization decision of the hotel chains, based on NUTS III data subjected to multivariate linear regression analysis.

In a second stage, applying the same techniques, but at the level of the counties and considering only the variables of agglomeration and knowledge, a direct comparison was made with the previous study, for verifying statistical evidence that confirm the relation between the variables in analysis with the internationalization of the hotel industry. Subsequently, the same variables were used to measure the impact on the proportion of international tourists received, annually, using the graphical representation.

In a third stage, considering the variables previously studied, and adding others i.e., import, export and temperature, also applied in scientific studies related to tourism, a logistic regression analysis was performed to estimate the probability associated to the internationalization decision of the hotels or establishment of foreign hotel chains in Portuguese territory.

The results obtained in the first article allow us to conclude that the agglomeration of firms related to the tourism sector is statistically significant, whereas only some knowledge and endogenous resources are statistically significant for the internationalization of the hotel sector. 
In the second article it is verified that the agglomeration continues to be statically significant for the internationalization of the hotels, as well as some knowledge resources. It is also verified, at the level of the proportion of international tourists, that the agglomeration and some resources of knowledge are statistically significant. The maps characterize the counties according to the variables under study.

In the third article, it is concluded that the existence of a high degree of knowledge, access to inherited or acquired resources and participation in international trade, affects the probability of internationalization of the hotel industry, while the probability of establishing foreign hotels varies according to the level of international trade, natural and historical-cultural resources and the climate of the regions.

Keywords: Tourism - Internationalization - Hotel industry - Knowledge · International Tourists · Foreign Investment - MLR analysis - Logistic Regression 


\section{Resumo}

Com a aquisição do direito de livre circulação de pessoas e comércio e com a diminuição das barreiras económicas, políticas e sociais, o turismo demonstrou-se um mecanismo de geração interna de riqueza. Contudo, as constantes mutações do espaço económico e a saturação do mercado interno, exigiu ao setor turístico uma maior competitividade e aplicação de inovação e diferenciação nos seus produtos/serviços.

Para subsistirem no mercado, e manterem o seu posicionamento competitivo, a indústria hoteleira, viu nas suas vantagens internas uma oportunidade de explorar mercados internacionais, pelo que, ao longo dos anos, a internacionalização do turismo e o seu potencial impacto no desenvolvimento económico e social das regiões, assim como as suas determinantes, têm vindo a ser alvo de aprofundamento por parte dos estudiosos.

Apesar do elevado contributo, deste segmento de atividade, para o desenvolvimento da economia, são ainda verificadas muitas desigualdades, não sendo o fluxo turístico, a internacionalização ou fixação de cadeias hoteleiras estrangeiras proporcional em todas as regiões portuguesas. Neste sentido, a literatura enumera algumas variáveis que podem explicar este fenómeno, como o nível educacional, conhecimentos partilhados e experiências adquiridas pelos recursos humanos; o grau de aglomeração de empresas do setor turístico e de produtos complementares; fatores macroeconómicos subjacentes à economia ou, até mesmo, recursos herdados/adquiridos ou fatores climatéricos.

De forma a averiguar o impacto das determinantes, na indústria hoteleira e nos fluxos de turismo, foram realizados três estudos diferentes, sendo um deles elaborado ao nível das NUTS III e os restantes ao nível dos municípios, existindo uma comparação de resultados para o ano de referência.

Numa primeira fase, com o intuito de verificar se existem evidências estatísticas para afirmar que as variáveis validadas pela literatura, i.e. aglomeração, conhecimento e recursos turísticos, são significativas para a decisão de internacionalização das cadeias hoteleiras, utilizou-se a base de dados por NUTS III e a análise de regressão linear multivariada.

Numa segunda fase, aplicando a mesma técnica de análise, mas ao nível dos municípios e considerando apenas as variáveis de aglomeração e conhecimento, efetuou-se uma comparação direta com o estudo anterior, para a verificação de evidências estatísticas que afirmem a relação das variáveis em análise com a internacionalização da indústria hoteleira. Ainda nesta segunda etapa, as mesmas variáveis foram estudas para medir o impacto na proporção de turistas internacionais recebidos anualmente pelo país e a representação gráfica será elaborada.

Numa terceira fase, considerando as variáveis até então estudadas, e acrescentando outras i.e., importação, exportação e temperatura, também aplicadas em estudos científicos relacionados ao turismo, realizou-se uma análise de regressão logística para estimar a probabilidade associada à decisão de internacionalização dos hotéis ou estabelecimento de cadeias hoteleiras estrangeiras em território português. 
Os resultados obtidos no primeiro artigo, permitem concluir que a aglomeração de empresas relacionadas ao setor do turismo é estatisticamente significativa, enquanto que, apenas alguns recursos de conhecimento e endógenos são estatisticamente significativos para a internacionalização do setor hoteleiro.

No segundo artigo, verifica-se que a aglomeração continua a ser estaticamente significativa para internacionalização dos hotéis, assim como alguns recursos de conhecimento. Verifica-se, igualmente, ao nível da proporção de turistas internacionais que a aglomeração e alguns recursos de conhecimentos são estatisticamente significativos. Os mapas caracterizam os municípios de acordo com as variáveis em estudo.

No terceiro artigo, conclui-se que a existência de um elevado grau de conhecimento, acesso a recursos herdados ou adquiridos e a participação no comércio internacional, afetam a probabilidade de internacionalização da indústria hoteleira, enquanto que a probabilidade de estabelecimento de hotéis estrangeiros varia de acordo com o nível de comércio internacional, recursos naturais e histórico-culturais e o clima das regiões.

Palavras-chave: Turismo - Internacionalização - Indústria hoteleira - Conhecimento - Turistas Internacionais · Investimento Estrangeiro · Regressão Linear · Regressão Logística 


\section{Chapter I}

\section{Introduction}




\section{Presentation and Opportunity of the theme}

At the beginning of time, the human kind has moved from one territory to another, freely, for various reasons, ignoring the notion of boundaries and territoriality. However, due to the sedentary lifestyle, humans began to idealize the definition of border and territory, and when it began to move with certain regularity and for specific reasons, i.e. leisure, rest or knowledge of other cultures, the need to create an economic activity emerged, nowadays named as tourism (Monteiro, 2014).

With the transition from a central planning system to a market economy, tourism has undergone complex and difficult changes (Williams, 2002), leading to a growing research to understand the processes of change (Hall, 1998), in terms the democratization of society and politics, which made the right of free movement within and outside a country accessible to citizens (Jaakson, 1996). The reduction of political barriers to trade and other areas of activity, such as tourism, since the midtwentieth century has led to the creation of an area of cross-border cooperation and innovation, characterized by the long-term creation of competitive advantages and an increase of the knowledge and skills flow resulting from human mobility across borders (Lundquist et al., 2006).

With the globalization of tourism markets and the international positioning of firms, the Portuguese economy, as well as the regions, benefited from positive externalities. However, international competition conditions continually require the industry to implement differentiating and innovative strategies that encourage the hotel chains' entry into new markets and the attraction of foreign capital to the country, as well as an increase in the flow of domestic and foreign tourists.

From the dynamics of the hotel industry and the importance of the internationalization of the tourism sector, due to its business structure, consisting essentially of small and medium-sized firms, several studies have resulted (Marco-Lajara et al., 2017; Marco-Lajara et al., 2016; Chen, 2016) with the intention of ascertaining the macroeconomic determinants and resources that characterize the regions with the greatest competitiveness and economic development. The exploitation of international competitive advantages and the capture of hotel multinationals, due to the agglomeration economies of the industrial sector, which allow the establishment of links of cooperation and exchange of knowledge beneficial to the activity, allowed tourism tendentially of standardized mass to evolve to standards more individualistic, presenting greater flexibility and significant experiences (Hummelbrunner et al., 1994).

In this sense, the establishment of interactions among firms, people and institutions allows the diffusion of knowledge and innovation across borders (Hall et al., 2008), marked by different political, ideological, administrative, economic and social systems that can influence tourism (Timothy et al., 2003). 


\section{Innovation Contribution}

The growing investment in establishing cooperation networks for the development and strengthening of the international tourism industry results from the belief that competitive advantages can be achieved through the exploitation of joint efficiency (Nordin, 2003), making it possible to acquire knowledge, experience, capital and other resources (Bramwell et al., 2000) essential for the promising growth of tourism in the world economy.

Despite the increase in scientific studies in the internationalization of tourism (Assaf et al., 2015; Williams et al., 2011) and the understanding of factors contributing to disparities in economic growth in different regions, there are few literary studies focused on internationalization of the Portuguese hotel chains and in the capture of foreign direct investment promoted by the human resources, endogenous and macroeconomic factors intrinsic to the territory and the Portuguese economy. In turn, the consideration of the proportion of foreign tourists who visit the country, annually, allows gauging the characteristics with the greatest consideration in the choice of the tourist region by the visitor.

In this way, to deepen and identify indicators that directly or indirectly contribute to the penetration of hotel chains into new markets, the establishment of multinationals in Portuguese territory, as well as the capture of international tourists in more general terms (NUTS III) and in more detailed terms (by counties) allows the recognition of the internal advantages that allow the affirmation of certain regions to the detriment of others, less driven by the touristic segment and the firms of complementary products.

\section{Main Objectives}

Considering all the points and issues studied by the scientific literature related to the internationalization of tourism, this dissertation aims to contribute, in a general way, to the identification, in national and regional terms, of the determinants of the internationalization decision of the hotel industry and the establishment of foreign business investment. On the other hand, it is required to verify if the proportion of foreign tourists is affected by certain variables related to the internationalization of the touristic sector.

Thus, in order to achieve the central objective, the following specific objectives will be pursued:

- At NUTS level III:

- Chapter II

(a) Analyze the statistical significance of the agglomeration of similar firms in the tourism sector for the internationalization of hotels;

(b) Analyze the statistical significance of knowledge resources and qualification of human resources for the internationalization of hotels;

(c) Analyze the statistical significance of touristic resources, i.e. natural, historical-cultural and capital resources for the internationalization of hotels; 
- At the counties level:

- Chapter III

(a) Analyze the statistical significance of the agglomeration of firms related to the tourism sector for the internationalization of hotels and attracting international tourists;

(b) Analyze the statistical significance of knowledge resources and qualification of human resources for the internationalization of hotels and attracting international tourists;

(c) Characterize counties through maps to visualize the distribution of the variables under study.

- ChapterIV

(a) Analyze the probability of agglomeration in the internationalization of hotel chains and foreign investment fixation;

(b) Analyze the probability of knowledge resources, i.e. number of courses related to the sector, in the decision to internationalize hotel chains and establish foreign investment;

(c) Analyze the probability of touristic resources, i.e. natural, historical-cultural and capital resources for the decision to internationalize hotel chains and establish foreign investment;

(d) Analyze the likelihood of macroeconomic factors, i.e. import and export for the internationalization or establishment of foreign hotels;

(e) Analyze the probability of climatic factors in attracting foreign direct investment.

\section{Methodology}

In order to study the specific objectives previously proposed, statistical data were collected on the various variables, both at NUTS III level and at counties level. After such collection and analysis, two databases were built, with reference to the year 2015.

The first article, entitled "Internationalization Strategies for Tourism in Portugal", is a quantitative study that analyses, at NUTS III level, the statistical significance of the variables mentioned in the objectives, in the internationalization decision of Portuguese hotels, using multivariate linear regression analysis.

The second article "Internationalization Innovative Strategies for Tourism in Portugal: Municipal Analysis and International Tourists", also quantitative and using the multivariate linear regression analysis, analyses at the county level, the statistical significance of the variables defined for the internationalization of hotels and attraction of tourists. Also, through the RStudio, the graphical representation of the counties characterization will be presented.

Finally, the third article "When Hotels go Abroad: The Internationalisation of the Portuguese Hospitality", studies in quantitative terms the probability of the study variables affecting the internationalization or establishment of foreign hotels in the country, through a logistic regression analysis. 


\section{Structure}

This document is structured in 5 chapters. In the first chapter an introduction is made to the subject under study, as well as its contribution, the main objectives to be achieved and the methodology used for the elaboration of the dissertation.

The second chapter is dedicated to the article "Internationalization Strategies for Tourism in Portugal", while the third and fourth chapter are reserved for the exhibition of the articles "Internationalization Innovative Strategies for Tourism in Portugal: Municipal Analysis and International Tourists" and "When Hotels go Abroad: The Internationalisation of the Portuguese Hospitality", respectively. The fifth and last chapter, includes the main conclusions, discussion of results and future research proposals.

\section{References}

Assaf, A. G., Josiassen, A., \& Agbola, F. W. (2015). Attracting International Hotels: Locational Factors That Matter Most. Tourism Management 47, 329-340.

Bramwell, B., \& Lane, B. (2000). Tourism Collaboration and Partnerships: Politics, Practice and Sustainability. Clevedon: Channel View Publications.

Chen, M.-H. (2016). A quantile regression analysis of tourism market growth effect on the hotel industry. International Journal of Hospitality Management 52, 117-120.

Hall, C. M., \& Williams, A. M. (2008). Tourism and Innovation. London: Routledge.

Hall, D. R. (1998). Tourism Development and Sustainability Issues in Central and South-Eastern Europe. Tourism Management, 423-431.

Hummelbrunner, R., \& Miglbauer, E. (1994). Tourism Promotion And Potencial In Peripheral Areas: The Austrian Case. Journal Of Sustainable Tourism, 41-50.

Jaakson, R. (1996). Tourism In Transition In Post-Soviet Estonia. Annals of Tourism Research 23. 617-634.

Lundquist, K.-J., \& Winther, L. (2006). The Interspace Between Denmark and Sweden: The Industrial Dynamics of the Oresund Cross-Border Region. Journal of Geography, 115-129.

Marco-Lajara, B., Claver-Cortés, E., Úbeda-García, M., \& Zaragoza-Sáez, P. D. (2016). Hotel Performance and Agglomeration of Tourist Districts. Regional Studies 50, 1016-1035.

Marco-Lajara, B., Zaragoza-Sáez, P. d., Claver-Cortés, E., Úbeda-García, M., \& García-Lillo, F. (2017). Tourist Districts And Internationalization Of Hotel Firms. Tourism Management 61, 451-464.

Monteiro, W. L. (2014). Avaliação de Destinos Turísticos - 0 Caso do Turismo de Natureza da Guiné-Bissau. Universidade Fernando Pessoa, 1-112.

Nordin, S. (2003). Tourism Clustering \& Innovation. Sweden: European Tourism Research Institute.

Timothy, D. J., \& Tosun, C. (2003). Tourists' Perceptions Of The Canada-USA Border As a Barrier To Tourism At The International Peace Garden. Tourism Management, 411-421. 
Williams, A. M. (2002). The Czech and Slovak Republics: Conceptual issues in the economic analysis of tourism in transition. Tourism Management 23, 37-45.

Williams, A. M., \& Shaw, G. (2011). Internationalization and Innovation in Tourism. Annals of Tourism Research 38, 27-51. 


\section{Chapter II}

\section{Internationalization Strategies for Tourism in Portugal}

Published in Innovation, Engineering and Entrepreneurship. HELIX 2018. Lecture Notes in Electrical Engineering, vol. 505. Springer, Cham. (2019) https://doi.org/10.1007/978-3-319-91334-6_134 


\title{
Internationalization Strategies for Tourism in Portugal
}

\author{
Anabela Oliveira, Vítor Braga, and Eliana Costa e Silva \\ CIICESI, ESTG/P.PORTO - Centre for Innovation and Research in Business \\ Sciences and Systems Information, School of Technology and Management, \\ Polytechnic of Porto, Porto, Portugal \\ $\{8130100$, vbraga, eos\}@estg.ipp.pt
}

\begin{abstract}
Tourism is one of the activities of great relevance on a global scale; with an increasing and fierce competition, needing to attract national and international tourists to maintain its distinctive position. Being considered as the Portuguese economy's booster, and as a strong strategic activity for the future development of the country it is required to verify if: the agglomeration of tourism firms, the continuous investment on the qualification of human resource and the inherited and complementary resources influence the decision of the internationalization of the Portuguese hotels. The multivariate linear regression (MLR) analysis carried out for the Portuguese context, using a database of 2015, concludes that the agglomeration is statistically significant, whereas only some endogenous and knowledge resources are statistically significant for the internationalization of the sector.
\end{abstract}

Keywords: Tourism • Internationalization - Knowledge - MLR analysis

\section{Introduction}

In recent years, due to the gradual increase in the interest to study the internationalization of tourism, some models which explain the main factors that encourage the internationalization and globalization of tourism firms have been presented (Marco-Lajara et al., 2017; Chen, 2016). However, the globalization of tourism market, required the sector to implement strategies to improve its competitive position through cooperation for innovating and differentiating the product and/or service offered (Smeral, 1998). Despite the importance of the internationalization and survival of the sector in the global market, tourism is also considered an engine for regional development, which improves the endogenous characteristics of each region and promote the natural, cultural and historical heritage.

Considering these facts studied by Marco-Lajara et al., (2017) the present study intends to contribute to the identification of factors that may influence the decision of firms in the Portuguese tourism sector to expand abroad. To achieve the central objective, it is intended to respond the following specific objectives:

(a) Analyze the relationship between variables validated by literature, as well as the role of the concentration of firms of the sector in the Territorial Units (TU) of Portugal Continental (NUTS III) in the decision making for the internationalization of hotel chains; 
(b) Analyze the extent to which the agglomeration of firms and the training offer in the tourism sector in NUTS III generates knowledge and promotes employment, qualification, enhancement of human resources and influences internationalization;

(c) Identify the factors that motivate tourism firms to expand internationally, in terms of natural, historical-cultural and capital resources.

With a business structure mainly constituted by small and medium enterprises (SMEs), the Portuguese tourism sector reveals a huge capacity in the development, qualification of resources and territorial requalification, which allows the expansion of the Portuguese tourism sector. The decision to focus the study on TU and Portuguese tourism is due to the fact, that this is a segment driven by the external market and the first European country to be distinguished as the best touristic destination in 2017, by World Travel Awards. Every year, Portugal attracts millions of tourists, due to complementary product firms, but also to inherited and acquired resources (Mira et al., 2016). If the previously proposed objectives are achieved, the study will be able to elucidate the capacity that the agglomeration and the tourism resources exert in the process of internationalization of the segment.

The rest of this document is structured as followed: In Sect. 2, a theoretical approach based on several literary studies, and specifically in the study of Marco-Lajara et al., (2017) with the aim of understanding the motivations for the internationalization and globalization of Portuguese hotel chains. Moreover, the hypotheses for further investigation will also be proposed. In the third and fourth section, the methodology used and the main results of the study will be described. The final section presents the conclusions.

\section{Literature Review}

For firms, internationalization is the main strategy adopted to increase competitiveness, employment and to provide an environment conducive to economic growth and development of innovations. In general, this process represents their survival and prosperity in the market, by increasing long-term profitability and sustainability of competitiveness (Kubícková et al., 2014). In order to explain the initial decision of internationalization, resulting from several internal and external factors, there are different theories in the literature, namely, Uppsala model, based on the acquisition of knowledge, learning and experience resources resulting from the involvement with other external markets (Johanson et al., 1977); the theory of networks, which enhances the competitive capacity, learning and specialization through the establishment of collaboration networks (Coviello et al., 1997); and the eclectic paradigm that considers as main advantages for the firm to act in the international market, property, location and internalization (Dunning, 1988). In this sense, the success of the internationalization strategy is directly related to the capacities and resources that a firm holds (Wernerfelt, 1984). 
Considered by organizations as a relevant factor in the decision-making process, the agglomeration represents externalities, i.e. access to resources, better suppliers of goods and services, expansion of the network of relationships and knowledge, and improvements in the demand (Canina et al., 2005). In this way, hotels tend to be located in urban areas or tourist destinations, where tourism is one of the main economic sectors, and where geographic characteristics (Mira et al., 2016) are favourable, forming an economy of location.

With the stagnation of the domestic market and small opportunities provided by it, the firms that belong to these agglomerations have competitive advantages at the national level and tend to be influenced to penetrate external markets (Wang et al., 2004), to strengthen its competitive capacity and to exploit its advantages at an international level, through its own resources and the ones provided by the country in which it intends to operate. Considering this, the first hypothesis proposed for research will be:

H1. the number of internationalized hotels will be higher in the TUs with a greater degree of tourism firms'agglomeration.

Seen as one of the most important intangible resource for organizations, knowledge can be generated through internal learning processes or acquired through cooperation with more experienced organizations that belong to the sector of activity, and it is also considered as one of the most important factors in internationalization theories (Prashantham, 2005), such as the Uppsala model, in which it is considered as an instrument to reduce uncertainty in the commitment to the market and to identify opportunities at the international level. The increasing competitive advantages resulting from the knowledge and qualified human and intellectual resources in the area, influence the firm to expand to new markets, which leads to the formulation of the following hypothesis:

H2. the number of internationalized hotels will be higher in the TUs that generate knowledge related to the sector, measured by the number of universities (H2a), professional training institutions $(H 2 b)$ and research and development (R\&D) centres $(H 2 c)$, which generate specific knowledge for the sector.

Although the knowledge resources are important for the sustainability of tourism firms, the characteristic resources of a region contribute to attract tourists, since they present themselves as more attractive and more successful destinations. The services and hotels, seek to locate in territories close to the markets and potential customers, as well as in central locations where there are several services and tourist attractions, access to inherited resources (Mira et al., 2016) and infrastructure with complementary products (Papatheodorou, 2001). This motivated the following research hypothesis: 
H3. the number of internationalized hotels will be higher in the territorial units that have more resources, specifically: more natural resources, i.e. beaches and protected areas (H3a), greater number of historical-cultural resources, i.e. monuments and museums $(H 3 b)$ and greater number of capital resources, i.e. activities and thematic parks $(H 3 c)$.

\section{Research Methodology}

Previously applied by several studies in tourism (Chi et al., 2008; Gross et al., 2008), MLR analyses the relationship between a dependent variable and a set of independent variables. The statistical software SPSS (version 23) was used. The purpose was explaining to what extent the sources of technical and specific knowledge for the tourism sector and tourism resources in Portugal are significant or not for the internationalization of Portuguese hotel chains in 2015. To test the hypotheses of the previous section, a MLR model is proposed, focused on the internationalization of Portuguese hotel, for $H /$ to $H 2$.

$H O T_{-} I n t=\beta_{1} A g g+\beta_{2} U I+\beta_{3} M L I+\beta_{4} R \& D+\varepsilon$

and for $H 3$.

$H O T_{-} I n t=\beta_{5} N R+\beta_{6} H C R+\beta 7 C R+\varepsilon$

where $\beta_{1} \ldots . . \beta_{7}$ are the coefficients of the explanatory variables, $\varepsilon$ is the residual variable with normal distribution, HOT_Int the number of internationalized hotels; Agg the agglomeration, UI the university institutions; $M L /$ the middle-level institutions; $R \& D$ the centres of Research and Development; NRthe natural resources; $H C R$ the historical-cultural resources and $C R$ the capital resources.

The population comprises all level III TUs from Portugal. With support in the main Portuguese databases, namely the Instituto Nacional de Estatistica (INE), 25 TUs were identified, two of which were excluded from the study ${ }^{1}$. Thus, the study sample comprises 23 TUs, 10 located in the coastal and the remaining 13 in interior areas.

Dependent Variable. To identify the hotels, that took the decision to internationalize, belonging to each TU in study, the database of Turismo de Portugal (TP) was used, where was collected the list of hotels existing in Portugal Continental. This list and the respective website of each hotel, allowed recognizing the TU of origin of each internationalized hotel. Only 59 internationalized hotels for a total of 1024 were identified, and 49 are concentrated in the great centres and on the coastal zone.

\footnotetext{
1 The autonomous regions were excluded due to lack or confidentiality of information.
} 
Independent Variables. As proposed by Marco-Lajara et al. (2017), the agglomeration of each TU was calculated as follows:

$$
\operatorname{Agg}_{i}=\frac{\text { Employment sector tourism in TU i }}{\text { Total employment in TU i }}: \frac{\text { Employment sector tourism in Portugal }}{\text { Total employment in Portugal }}
$$

To measure knowledge resources, the number of higher education and professional training institutions, as well as R\&D centres related to the tourism sector, was considered in each TU, and all the information, was collected directly from the website of Direção Geral de Estatística $e$ Educação para a Ciência and Direção Geral dos Estabelecimentos Escolares. Knowledge resources were measured as:

- Universities and Polytechnics - number of institutions in each TU that confer academic degree in tourism, relativized by 100,000 inhabitants;

- Middle-level schools - number of institutions in each TU with vocational training in tourism, per 100,000 inhabitants;

- R\&D centres - number of public and/or private research centres in each TU in the tourism segment.

It is also intended to study the resources that may influence the decision to internationalize. The data collection was made from the TP website and from the statistical portal INE. The resources were measured as:

- Natural resources - number of protected areas, gardens, parks and beaches;

- Historical-cultural resources - number of monuments and museums;

- Capital resources - number of tourist activities and theme parks of each TU.

\section{Analysis and Discussion of the Results}

As the study sample is small and presents a non-normal distribution, the non-parametric Spearman correlation test was used to study the correlation between the dependent variable HOT_Int - and each of the independent variables. Table 1 shows the existence of a possible positive association between all the independent variables and the response variable, which is statistically significant for most of the variables. These values suggest the validation of the hypotheses previouslystated.

\footnotetext{
2 Data on employment and unemployment in the country, of each TU in study, corresponding to economic activity codes 55 and 56 - hotels, catering and tourism.
} 
Table 1. Spearman Correlation (non-parametric test) with the dependent variable HOT_Int.

\begin{tabular}{ll|ll}
\hline Variables & Coefficients & Variables & Coefficients \\
\hline Agglomeration & $0.407^{\star}$ & PhD tourism & $0.403^{\star}$ \\
University inst. & 0.068 & Professional courses & $0.383^{\star}$ \\
Prof. Training inst. & 0.192 & Natural resources & 0.208 \\
R\&D centres & 0.345 & Historical-cultural & $0.431^{\star \star}$ \\
Graduation tour. & $0.433^{\star \star}$ & resources & \\
Masters tourism & $0.634^{\star \star *}$ & Capital resources & $0.436^{\star \star}$ \\
\hline$* * *<0.01 * * *<0.05^{*} p<0.1$ & &
\end{tabular}

${ }^{* * \star} p<0.01 ;{ }^{* \star} p<0.05 ;{ }^{*} p<0.1$

The results for the MLR models are depicted in Table 2. Model 1 indicates that the agglomeration explains $56.3 \%$ of the variability of the internationalization of hotels. Including in this model the variables related to knowledge resources (model 2), $68.4 \%$ of hotels internationalization is explained by independent variables, while in model 3 , the explained percentage is $57.4 \%$, suggesting that knowledge generated by the firms presented in a cluster is an important factor for the internationalization. Finally, model 4 indicates that $48.2 \%$ of hotels internationalization is explained by natural, historical-cultural and capital resources. Using stepwise method for eliminating the non-statistically significant variables obtained for the models ( 1 to 3 ), the agglomeration is the only variable with a positive coefficient and statistically significant, i.e. the hotel chains that tend to internationalize, in TU with higher agglomeration, while contrary to the expected the professional training Institutions have a negative impact.

Table 2. MLR model results.

\begin{tabular}{|c|c|c|c|c|c|}
\hline Independ. Var. & Model 1 & Model 2 & Model 3 & Independ. Var. & Model 4 \\
\hline Agglomeration & $0.639^{\star \star \star}$ & $1.215^{\star \star \star}$ & $1.897^{\star \star \star}$ & Natural resources & $0.025^{\star \star}$ \\
\hline University Inst & & -0.171 & & & \\
\hline Prof. Inst. & & $-0.317^{\star \star}$ & & Historical-cultural & 0.001 \\
\hline R\&D Centres & & 0.139 & $0.542^{*}$ & resources & \\
\hline Grad + Master & & & -0.017 & & \\
\hline PhD Tourism & & & 0.077 & Capital resources & -0.001 \\
\hline Prof. Courses & & & -0.013 & & \\
\hline $\mathrm{F}$ & $30.675^{\star \star \star}$ & $13.473^{\star \star \star}$ & $7.186^{* \star *}$ & $F$ & $8.126^{* \star *}$ \\
\hline $\mathrm{R}^{2}{ }_{\mathrm{a}}$ & 0.563 & 0.684 & 0.574 & $\mathrm{R}^{2} \mathrm{a}$ & 0.482 \\
\hline DW & 1.406 & 1.591 & 1.897 & DW & 1.488 \\
\hline
\end{tabular}

As for variables that measure knowledge generated through universities (H2a) and R\&D centres (H2c), studied by Marco-Lajara et al. (2017) for Spain, do not have a representation in the Portuguese context, which indicates the non-verification of $H 2$, i.e., there is no statistical 
significance that the Portuguese hotels take advantage of the knowledge to internationalize. Given that the variables under study for this topic did not allow to verify the hypothesis, four proxy variables were introduced, namely the number of courses (graduation, masters, PhD and professional courses) that each institution offers in tourism areas. Model 3 shows that there is a positive relationship between the courses offered in the area (PhD) and R\&D centres, in the internationalization of hotels, however, only R\&D centres are statistically significant, which leads to the verification of $H 2 c$. Finally, natural and historical-cultural resources have a positive impact on the internationalization of Portuguese hotels, while capital resources have a negative impact, only the natural resources variable is statistically significant, with $H 3 a$ being verified.

For all models, the Durbin-Watson (DW) indicator shows that the residuals are not correlated $(D W<2)$. By means of the Kolmogorov-Smirnov test, it was verified that for a level of significance of $10 \%$, the residual variable follows a normal distribution. It was also observed the existence of one multivariate outlier in model 2 (Leverage value $>0.5$ ), three in model 3 and in model 4 , two multivariate outliers. These outliers can contain relevant information about population, reason why they were not excluded. In all models, the VIF values are less than 10 and the Condition Index is small, thus verifying the absence of multicollinearity.

\section{Conclusions}

In general, industries and hotel sector, tend to locate in territories in which exist, or are generated, resources favourable to the activity i.e. in areas where the concentration of similar or complementary activities are agglomerated, allowing the creation of competitive advantages internally or through interaction with firms with specific knowledge, belonging to the cluster. In this sense, the results presented confirm, from the practical point of view and for the Portuguese hotel context, the hypothesis that hotels tend to internationalize when they are in TU with more agglomeration.

Despite the fundamental role attributed to knowledge in the literature, in the process of internationalization, and in Marco-Lajara et al. (2017) for the Spanish territory, it was not possible to obtain similar evidences for Portugal. We believe that there are disparities in terms of geography, population, employment and infrastructures in each TU, which may contribute to the skew of the study. Thus, according to the results obtained for this hypothesis, the specific knowledge in the activity sector does not have a vital role in the internationalization decision of the hotel sector, although it has a certain importance given the need for qualified resources and research for the business development. Also considering the introduction of new variables in the study, as natural, historical-cultural and capital resources, may have an influence on the location of tourism enterprises, since it contributes to attracting tourists and the improvement of the supply, but do not have in totality a significant role in the decision to internationalize. In the future, 
we intend to refine the model by reclassifying the resources present in each category of study, as well as expanding the sample under study.

In summary, for the Portuguese hotel sector, only the agglomeration translates into a strategic advantage for internationalization, while knowledge and endogenous resources are neglected, evidencing the existence of factors with greater importance in the internationalization decision. In theoretical terms it can translate into survival to the country's economic crisis, saturation of opportunities in the domestic market, or just a means to mitigate uncertainty or increase the profitability of the business.

\section{References}

Canina, L., Enz, C.A., Harrison, J.: S.: agglomeration effects and strategic orientations: evidence from the U.S. lodging industry. Acad. Manag. J. 48, 565-581 (2005)

Chen, M.-H.: A quantile regression analysis of tourism market growth effect on the hotel industry. Int. J. Hosp. Manag. 52, 117-120 (2016)

Chi, C.G.-Q., Qu, H.: Examining the structural relationships of destination image, tourist satisfaction and destination loyalty. Tour. Manag. 29, 624-636 (2008)

Coviello, N., Munro, H.: Network relationships and the internationalisation process of small software firms. Int. Bus. Rev. 6, 361-386 (1997)

Dunning, J.H.: The eclectic paradigm of international production: a restatement and some possible extensions. J. Int. Bus. Stud. 19, 1-31 (1988)

Gross, J., Brown, G.: An empirical structural model of tourists and places: progressing involvement and place attachment into tourism. Tour. Manag. 31, 1141-1151 (2008)

Johanson, J., Vahlne, J.E.: The internationalization process of the firm: a model of knowledge development and increasing foreign market commitments. J. Int. Bus. Stud. 8, 23-32 (1977)

Kubícková, L., Votoupalavá, M., Toulová, M.: Key motives for internationalization process of small and medium-sized enterprises. Procedia Econ. Financ. 12, 319-328 (2014)

Marco-Lajara, B., Zaragoza-Sáez, P., Claver-Cortés, E., Úbeda-García, M., García-Lillo, F.: Tourist districts and internationalization of hotel firms. Tour. Manag. 61, 451-464 (2017)

Marco-Lajara, B., Claver-Cortés, E., Úbeda-García, M., Zaragoza-Sáez, P.C.: Hotel performance and agglomeration of tourist districts. Reg. Stud. 50, 1016-1035 (2014)

Mira, M.R., Moura, A., Breda, Z.: Destination competitiveness and competitiveness indicators. TÉKHNE - Rev. Appl. Manag. Stud. 14, 90-103 (2016)

Papatheodorou, A.: Why people travel to different places. Ann. Tour. Res. 28, 164-179 (2001)

Prashantham, S.: Toward a: knowledge-based conceptualization of internationalization. Int. Entrep. Manag. J. 3, 37-52 (2005)

Smeral, E.: The impact of globalization on small and medium enterprises: new challenges for tourism policies in European countries. Tour. Manag. 19, 371-380 (1998) 
Wang, S.Q., Dulaimi, M.F., Aguria, M.Y.: Risk management framework for construction projects in developing countries. Constr. Manag. Econ. 22, 237-252 (2004)

Wernerfelt, B.: A resource-based view of the firm. Strateg. Manag. J. 5, 171-180 (1984) 


\section{Chapter III}

\section{Internationalization Innovative Strategies for Tourism in Portugal: Municipal Analysis and International Tourists}




\title{
Internationalization Innovative Strategies for Tourism in Portugal: Municipal Analysis and International Tourists
}

\author{
Anabela Oliveira, Vítor Braga, and Eliana Costa e Silva \\ CIICESI, ESTG/P.PORTO - Centre for Innovation and Research in Business \\ Sciences and Systems Information, School of Technology and Management, \\ Polytechnic of Porto, Porto, Portugal \\ $\{8130100$, vbraga, eos\}@estg.ipp.pt
}

\begin{abstract}
The continuous increase of the tourism sector in Portugal and the diversification of destinations in national and international markets, promotes the reinforcement of new hotels chains in the country and requires innovative strategies that contrast with the traditional ones. However, the occupation rate and the growth of demand, it's not proportional since some regions attract more hotels and tourists than others. In this case, it is required to verify considering all counties if: the agglomeration of hotels and the continuous investment on the qualification of human resources influences the decision of the internationalization of the Portuguese hotels and if these conditions contribute to attract more international tourists for the country. The multivariate linear regression (MLR) analysis, using a database of 2015 disaggregated by counties, concludes that the agglomeration is statistically significant, whereas only some knowledge resources are statistically significant for the internationalization of the tourism sector and attraction of international tourists. The graphical representation characterizes the counties in study.

Keywords: Internationalization - Knowledge - Tourism - MLR analysis - International Tourists • Innovation
\end{abstract}

\section{Introduction}

Over the years, the democratization of society and politics gave to citizens the right of freedom of movement (Jaakson, 1996), creating an area of integrated innovation, characterized by a flow of knowledge and resulting in an increased human mobility across borders (Lundquist et al.,, 2006). In this sense, the highly dynamic tourism sector, which is willing to explore its competitive advantages and resources in external markets (Marco-Lajara et al., 2017) had a huge impact on the development of economies.

Considering these facts, the previously study by NUTS III (Oliveira et al., 2019) and the existing literature, this study aims to contribute to the identification of the factors that encourage the internationalization of the Portuguese tourism sector and the attraction of international tourists, considering the same research hypotheses defined in Marco-Lajara et al., (2017). In order to achieve the central objective, the following specific objectives will be pursued:

(a) to analyse and compare with the previously study by NUTS III, the role of the agglomeration of firms and the extent to which the educational institutions and the training offer generate knowledge to support the internationalization decision of the hotels chains; 
(b) to analyse the role of the agglomeration of firms and the extent to which the educational institutions and the training offer, by counties, contribute to attract international tourists;

(c) characterize counties through maps generation;

Thus, once the objectives are met, the study contributes to clarify to what extent the internationalization of Portuguese tourism firms and the attraction of international tourists contribute to the country's affirmation internationally and to the exploration and development of the counties.

The rest of this document is structured as followed: in section 2, based on the study of MarcoLajara et al., (2017), for Spain and other related literary studies, a theoretical aproach will be developed to support the proposed the hypotheses for further investigation. In section 3 , the methodology used is explained and in section 4 the main results of the study will be described. The final section presents the conclusions.

\section{Literature Review}

\subsection{Internationalization of Hospitality}

The integration of markets and increasing competitiveness in the business context requires hospitality and tourism firms to develop new products / services and to engage in interorganizational networks. (Kandampully et al., 2016).

Marshall was the first studying the "geographic economies" or "Marshall economies", i.e., the concentration of firms belonging to the same industry in a specific geographic area, in order identify the reasons that led similar firms to group together in a territory and what the impacts on profitability and the externalities resulting from that concentration. (Marshall, 1890).

Due to the structure of the business fabric and the increasing dependence between organizations, participation in a network or cluster can represent, for hospitality, a strategic decision that allows access to resources / markets and cost reduction (Farsani et al., 2012; Kofler et al., 2018) inherent in the process of internationalization and innovation. Belonging to a network also allows the generation of value for all stakeholders, increasing flexibility and promoting interorganizational learning (Jesus et al., 2016).

The concentration and geographic cooperation of economies helps regional firms in the innovation process, since they do not innovate in isolation, but rather when they belong to a system where trust and knowledge are created and disseminated (Cooke et al., 1998; Doloreux et al., 2005).

Despite the importance of innovation in the tourism sector, to survive and increase their competitive efficiency, in a saturated market, tourism firms tend to locate in areas with greater agglomeration of firms of the sector, geographically and culturally close, to benefit from positive externalities (Boschma et al., 2006) and greater demand from foreign tourists (Yang et al., 2012). These skills and knowledge are fundamental to reduce risk and uncertainty (Nguyen et al., 2006) and provide access to new opportunities in foreign markets (Zhou et al., 2007). 
In this sense, the regions with the largest agglomeration of firms display more developed business environments and activities that facilitate the establishment of relations between national and multinational firms, offering specialized services that may be attractive for the internationalization of hotel chains (Burger et al., 2015). In view of the above, the first hypothesis proposed for research will be:

H1. The number of internationalized hotels will be higher in the counties with a greater degree of tourism firms'agglomeration.

In the business world, human capital is highly representative, with a positive relationship between education and organizational efficiency (Aziri et al., 2013). Despite being considered as a key factor in the tourism and hospitality industry, which is essentially labor-intensive, ie, through the pool of knowledge and skills, the recruitment of human capital is closely linked with collaboration, provided that this process ensures the provision of adequate staff for the service (Gokovali et al., 2012).

Tourism and hospitality firms with skilled labour have greater capacity for innovation (Grissemann et al., 2013), since the skills and knowledge of the employees allow the organization to adopt new technologies, generate and implement new ideas and organizational changes (López-Fernández et al., 2011). The innovation generated in the region is measured by data such as patents, $R \& D$ expenses, number of people with academic degree, among others (Kofler et al., 2018).

In addition, the intellectual capacities of employees are intrinsically linked to the firm's ability to develop and market new products/services, as well as to develop internally advantages that influence the process of exploring new markets (López-Fernández et al., 2011).

Since knowledge is disseminated among people, the investment in intellectual capital with higher professional qualifications and the development of learning programs within organizations, contributes not only to the training of the worker but also to the benefit of the firm. Several studies also indicate that knowledge is seen as a driver of internationalization (Papatheodorou, 2001) as firms have easy access to qualified human resources, which reduces learning expenses and improves the services provided to the final client. Considering the facts described, the second hypothesis of investigation will be:

H2. The number of internationalized hotels will be higher in the counties that generate knowledge related to the sector, measured by the number of universities (H2a), professional training institutions ( $H 2 b)$ and research and development (R\&D) centres (H2c), which generate specific knowledge for the sector. 


\subsection{Proportion of International Tourists}

During their life cycle in the market, firms belonging to the tourism industry tend to prefer to concentrate on locations that are beneficial to the business, i.e., low-cost locations and high demand (Baum et al., 1997) due to high competitiveness between firms and touristic destinations. This concentration of similar firms is motivated not only by the intrinsic characteristics of the region, but also by economies of agglomeration or location.

In hospitality, location economies, i.e. the positioning of a hotel in a location with several complementary services and businesses, will allow sharing of infrastructure and access to externalities. These externalities inform entrants in the hotel industry on demand in the regions and potential customers on the location of supply. Kalnins et al., (2004), indicate in their study that the benefits of agglomeration of tourism firms and access to resources play an important role in deciding the location of the hotel industry.

This geographic agglomeration of products/services enables tourism firms to reduce consumer demand costs and consequently increase demand for a region (Graitson, 1982), and it is found that counties that attract more tourism attract also more touristic firms.

The success in the market thus happens, to take advantage of the attractions of each touristic space and to collaborate with each other with the firms and activities of the location area. The adaptation of the structure to the potential tourists and the characteristics of the market, allows to manage the demand of the international tourists and the offer of touristic products. To this end, firms in agglomeration economies have a greater facility in adopting innovation strategies that allow the change and development of the touristic product/service, creating an image and attractiveness of the touristic area for international tourists. (Simonceska, 2012)

In this sense, the counties with the greatest agglomeration of hotel firms and complementary products/services, can stimulate the demand of the international tourists, since these regions usually have several services and characteristics that they want to experience. Through the stay in hotel establishments and use of existing services in the region, foreign tourists contribute to the development of different areas related to the tourism business. In view of the above, the third hypothesis proposed for research will be:

H3. The proportion of international tourists will be higher in the counties with a greater degree of tourism firms'agglomeration.

Recently, the tourism industry has been the target of numerous studies in the field of knowledge and in the production of tourist knowledge (Belhassen et al., 2009; Chambers et al., 2015). However, the research is still little applied, due to the difficulty of use and absorption or by not responding to the needs of the professionals of the area, which implies that the strategies offered to the hospitality industry are sometimes unclear for implementation. (Travesi, 2017) 
It is in this sense that constant technological innovation ensures communication at all stages of research and the effectiveness of knowledge transfer between universities and the tourism industry through collaborative research (Cooper, 2006; Xiao et al., 2007).

Knowledge and sharing of ideas combined with innovation results in the creation and offering of innovative touristic products and services, increasing the competitiveness of the firm and providing and managing information, with a focus on the customer and the quality of the service provided (Hardy et al., 2018).

As a valuable resource, it enables the tourism industry to exploit its intellectual assets and remove barriers to transfer and adoption of knowledge, which guarantees a specific local and cultural knowledge offer to international tourists.

These, in turn, seek places and activities not only to get to know the country but also to increase their intellectual capital, leading to the creation of specific areas of knowledge by tourism firms to contribute to its attraction.

The concern of the tourist, in the search for beneficial touristic destinations intellectually, requires the qualification of the professionals of the tourism sector individually, in personal and interpersonal terms, and in organizational terms, being this knowledge generated through internal or external processes (Freitas et al., 2012).

The acquisition and availability to international tourists, in the touristic destination, of tools of specific knowledge of the sector and tourist offer promotes the development of the local economy. The dissemination of local, social and cultural knowledge, as well as the satisfaction of the needs, expectations and concerns and the implementation of co-creation of touristic destinations with the final client, allows to loyalty and attract new groups of tourists to the region.

The growing concern about the implementation of strategies in the tourism sector for the attraction of foreign tourists based on knowledge contributes to the capitalization and profitability of the resources inherent to the territory, as well as the increase of the permanence of the tourists who value the acquisition of knowledge of different cultures and experiences in their travels (Julião, 2013). Considering the above, the fourth hypothesis of investigation will be:

H4. The proportion of international tourists will be higher in the counties that generate knowledge related to the sector, measured by the number of universities (H4a), professional training institutions $(H 4 b)$ and research and development (R\&D) centres (H4C), which generate specific knowledge for the sector.

\section{Methodology}

The MLR analysis is a tool already used previously in studies related to tourism (Marco-Lajara et al., 2017; Hershberger, 2003), in which the relationship between the dependent variable and a set of independent variables is analyzed. In this sense, statistical software SPSS 23 was used to analyze 
whether agglomeration and knowledge are significant for the internationalization of Portuguese hotels and attraction of international tourists to the counties.

To test the hypotheses of the previous section, a MLR model is proposed, focused on the internationalization of Portuguese hotels, for $\mathrm{Hland} H 2$.

$$
H O T_{-} I n t=\beta_{0}+\beta 1 A g g+\beta_{2} U I+\beta_{3} M L I_{+} \beta_{4} R \& D+\varepsilon \quad \text { (eq. 1) }
$$

and other focused on the proportion of international tourists, for $\mathrm{H} 3$ and $\mathrm{H} 4$ :

$$
P R O P_{-} N R e s=\beta_{0}+\beta 1 A g g+\beta_{2} U I+\beta_{3} M L I_{+} \beta_{4} R \& D+\varepsilon \quad \text { (eq. 2) }
$$

where $\beta_{0 . . .} \beta_{4}$ are the coefficients of the explanatory variables, $\varepsilon$ is the residual variable with normal distribution, HOT_Int the number of internationalized hotels; $A g g$ the agglomeration; $U I$ the university institutions; $M L /$ the middle-level institutions; $R \& D$ the centres of Research and Development and PROP_NResthe proportion of international tourists.

The population comprises all counties in Portugal, including the autonomous regions of Madeira and Azores, which were excluded in the previous study based on NUTS III (Oliveira et al., 2019) due to the confidentiality of data. Using the official data National Statistical Institute (INE - Instituto Nacional de Estatística), 308 counties were identified in Portugal, which is the sample under study.

Dependent variables. Using the same database, the previous study (Oliveira et al., 2019), in which the hotels internationalized were identified by NUTS III, through Turismo de Portugal, it was only necessary to identify to which county these 59 hotels belonged. For the inclusion of internationalized hotels in the regions of Madeira and the Azores, the county of origin was also identified, with only 9 internationalized hotels. In this sense, in total of 1164 hotels, only 68 decided to internationalize. The proportion of foreign tourists is one of the variables most referenced in the literature related to studies on the internationalization of tourism (Eilat et al., 2004; Chaisumpunsakul et al., 2018), and the statistical data used for each county was collected through INE. This variable presents 64 missing values due data confidentiality.

Independent Variables. As proposed in the Marco-Lajara et al., (2017) study, the agglomeration of each county was calculated as follows:

$$
\operatorname{Agg}_{i}=\frac{\text { Employment sector tourism in county }}{\text { Total employment in county }}: \frac{\text { Employment sector tourism in Portugal }}{\text { Total employment in Portugal }}
$$

To measure knowledge resources, the number of university institutions, professional training institutions and R\&D centres in each county, related to the tourism sector was considered. All information was collected from the website of General Direction of Statistics and Education for Science (DGEEC - Direção Geral de Estatística e Educação para a Ciência), General Direction of 
School Establishments (DGEstE - Direção Geral dos Estabelecimentos Escolares), Regional Directorate for Education (Direção Regional da Educação) and Regional Secretariat for Education (Secretaria Regional da Educação). Thus, knowledge resources were measured as:

- University and polytechnics: number of institutions in each county, which confer academic degree in tourism, relativized by 100.000 inhabitants;

- Professional training institutions: number of institutions, with vocational training in tourism, by county, relativized by 100.000 inhabitants;

- R\&D Centres: number of public and/or private research and development centres, by county.

\section{Analysis and Discussion of the Results}

\subsection{Internationalized Hotels}

Table 1 shows the minimums, maximums, medians, means, standard deviations, skewness and kurtosis for the dependent variable i.e., internationalized hotels and for each independent variable in study. In terms of skewness, the variables present a positive symmetrical distribution and a leptokurtic distribution in terms of "flattening". In this model, the Kline (1998) assumption does not occur, in which absolute values of skewness and kurtosis of less than 3 and 7 respectively indicate the normal distribution of the residues.

Table 1. Minimum, maximum, median, mean, standard deviation, skewness and kurtosis for the dependent variable HOT_Int.

\begin{tabular}{lccccccc}
\hline Variables & Min. & Max. & Median & Mean & $\begin{array}{c}\text { Std. } \\
\text { Deviation }\end{array}$ & Skewness & Kurtosis \\
\hline HOT_INT. & 0.0000 & 19.1607 & 0.0000 & 0.4226 & 1.8479 & 6.405 & 49.091 \\
Agglomeration & 0.2609 & 5.4978 & 0.8801 & 1.0723 & 0.7501 & 2.921 & 10.653 \\
Universityl. & 0.0000 & 11.3585 & 0.0000 & 0.4914 & 1.6361 & 4.019 & 17.723 \\
Professional I. & 0.0000 & 29.2826 & 0.0000 & 1.7185 & 3.6719 & 3.755 & 18.399 \\
R\&D Centres & 0.0000 & 2.0000 & 0.0000 & 0.03 & 0.204 & 7.685 & 63.322 \\
Grad. + Master & 0.0000 & 19.0000 & 0.0000 & 0.47 & 1.992 & 6.541 & 49.602 \\
PhD Tourism & 0.0000 & 5.0000 & 0.0000 & 0.04 & 0.341 & 11.605 & 154.119 \\
Professional & 0.0000 & 13.000 & 0.0000 & 0.65 & 1.406 & 4.683 & 29.971 \\
\hline
\end{tabular}

As in the previous study (Oliveira et al., 2019) and since the sample does not assume normality, the non-parametric Spearmancorrelation test (Table 2) was used to study the correlation between the dependent variable - HOT_Int - and each of the independent variables, which shows the existence of a possible positive association between all the independent variables and the response variable. However, since the sample has a significant dimension, we can invoke the 
central limit theorem, assuming its normality, and use the Pearson correlation, which also shows the existence of a possible positive association between the independent variables and the dependent variable. These values suggest the verification of the hypotheses previously stated.

Table 2. Pearson and Spearman Correlation with the dependent variable HOT_Int.

\begin{tabular}{lll}
\hline Dependent Variable & $H O T_{-} I n t$. & \\
Independent Variables & Pearson & Spearman \\
\hline Agglomeration & $0.364^{\star \star \star}$ & $0.285^{\star \star \star}$ \\
University Institutions & 0.041 & $0.186^{\star \star \star}$ \\
Professional Institutions & $0.184^{\star \star \star}$ & $0.248^{\star \star \star}$ \\
R\&D Centres & 0.033 & $0.164^{\star \star \star}$ \\
Graduation Tourism & 0.094 & $0.211^{\star \star \star}$ \\
Masters Tourism & 0.075 & $0.208^{\star \star \star}$ \\
PhD Tourism & $0.098^{\star}$ & $0.258^{\star \star \star}$ \\
Professional Courses Tourism & $0.182^{\star \star \star}$ & $0.343^{\star \star \star}$ \\
\hline${ }^{\star \star \star} p<0.01 ; *{ }^{* \star} p 0.05 ;{ }^{*} p 0.1$ & &
\end{tabular}

Table 3 summarizes the results for the MLR models of the dependent variable HOT_Int. In model 1 the agglomeration explains $14.6 \%$ of the variation of the internationalization of hotels in the counties. Including in this model knowledge variables (model 2 and 3), $15.6 \%$ and $15.5 \%$ of the variation of hotel internationalization is explained by the independent variables, respectively. Using the stepwise method to eliminate the statistically non-significant variables, for all models (1 to 3 ) the agglomeration presents a positive coefficient and statistically significant, i.e., internationalized hotels tend to locate in counties with higher concentration of touristic firms, being verified $H 1$.

Table 3. MLR model results for the dependent variable HOT_Int.

\begin{tabular}{|c|c|c|c|c|c|}
\hline Independ. Var. & Model1 & Model 2 & Model 2.1 & Model 3 & Model 3.1 \\
\hline Agglomeration & $0.559 * \star \star$ & $0.487^{\star \star \star}$ & $0.487^{\star \star \star}$ & $0.498^{\star \star \star}$ & $0.490^{\star \star \star}$ \\
\hline University Institutions & & 0.006 & & & \\
\hline Prof. Institutions & & $0.056^{\star \star}$ & $0.056^{* *}$ & & \\
\hline R\&D Centres & & -0.098 & & -0.255 & \\
\hline Grad + Master & & & & -0.033 & \\
\hline PhD Tourism & & & & 0.289 & \\
\hline Professional Courses & & & & $0.148^{\star}$ & $0.145^{\star \star}$ \\
\hline$F$ & $53.415^{\star \star *}$ & $14.502^{\star \star \star}$ & $29.173^{\star \star \star}$ & $11.764^{\star \star \star}$ & $29.140^{\star \star \star \star}$ \\
\hline $\mathrm{R}_{\mathrm{a}}{ }^{2}$ & 0.146 & 0.150 & 0.156 & 0.150 & 0.155 \\
\hline DW & 1.613 & 1.597 & 1.599 & 1.587 & 1.583 \\
\hline
\end{tabular}

In the analysis by counties there is a positive and statistically significant relationship between professional training institutions and the internationalization of hotels, which leads to the verification of $H 2 b$. Finally, with the introduction of the 4 proxy variables, there is a positive and statistically significant relationship between the professional courses offered in each county and the internationalization of Portuguese hotels, leading to the verification of $H 2 b$. 
For all models, the Durbin-Watson indicator shows that residues are not correlated (DW < 2). Through the Kolmogorov-Smirnov test, it is verified that for a significance level of $10 \%$, the residual variable holds a normal distribution. In all models, the VIF values are less than 10 and the Condition Index is small, and there is no multicollinearity. The models don't present multivariate outliers.

\subsubsection{Discussion}

Comparing the results of the linear regression obtained for the hotel internationalization at the municipal level, with the results of the previous study at the level of NUTS III (Oliveira et al., 2019), it is verified the agglomeration explains $14.6 \%$ of the variation of the internationalization of hotels in the counties, while in NUTS III, it explained $56.3 \%$. Including in the model the knowledge variables, $15.6 \%$ of the variation of hotel internationalization is explained by the independent variables, by counties, compared to $68.4 \%$ in NUTS III. Finally, while model 3 explains $15.5 \%$, by counties, $57.4 \%$ was explained by this variable in NUTS III. Thus, knowledge resources were more representative for the internationalization of hotels in NUTS III than in the analysis by counties.

For both studies, the agglomeration presents a positive coefficient and are statistically significant, i.e., internationalized hotels tend to locate in counties with higher concentration of touristic firms. Similarly, in the study of Marco-Lajara et al. (2017) for Spanish territory, this variable was validated.

Contrary to the results obtained in the analysis by NUTS III, in which no knowledge variable was validated, in the analysis by counties there is a positive and statistically significant relationship between professional training institutions and the internationalization of hotels, being this same variable validated in the study of Marco-Lajara et al. (2017).

With the introduction of the 4 proxy variables, it was verified the existence of a positive and statistically significant relationship between the professional courses offered in each county and the hotel internationalization, while in the model analysed based on NUTS III, R\&D centres were statistically significant for the internationalization of hotels.

\subsection{Proportion of International Tourists}

Table 4 shows the minimums, maximums, medians, means, standard deviations, skewness and kurtosis for the dependent variable PROP_Nres. and for each independent variable. The variables, in terms of skewness, present a positive symmetrical distribution and a leptokurtic distribution in terms of "flattening" for all variables, except for PROP_NRes, that presents a platykurtic distribution. The Kline (1998) assumption only occur for variable PROP_NRes, in kurtosis analysis. 
Table 4. Minimum, maximum, median, mean, standard deviation, skewness and kurtosis for the dependent variable PROP_Nres.

\begin{tabular}{lccccccc}
\hline Variables & Min. & Max. & Median & Mean & $\begin{array}{c}\text { Std. } \\
\text { Deviation }\end{array}$ & Skewness & Kurtosis \\
\hline PROP_Nres. & 0.0000 & 92.6 & 24.600 & 29.231 & 22.4243 & 0.795 & -0.039 \\
Agglomeration & 0.2609 & 5.4978 & 0.9110 & 1.1384 & 0.8128 & 2.674 & 8.525 \\
Universityl. & 0.0000 & 11.3585 & 0.0000 & 0.6136 & 1.8122 & 3.519 & 13.361 \\
Professional I. & 0.0000 & 29.2826 & 0.0000 & 1.8674 & 3.6545 & 3.785 & 19.680 \\
R\&D Centres & 0.0000 & 2.0000 & 0.0000 & 0.04 & 0.228 & 6.827 & 49.743 \\
Grad.+Master & 0.0000 & 19.0000 & 0.0000 & 0.59 & 2.216 & 5.819 & 39.076 \\
PhD Tourism & 0.0000 & 5.0000 & 0.0000 & 0.05 & 0.382 & 10.349 & 122.545 \\
Professional & 0.0000 & 13.0000 & 0.0000 & 0.77 & 1.536 & 4.302 & 24.859 \\
\hline
\end{tabular}

In Table 5, the dependent variable - PROP_NRes - through both correlation tests, also shows a possible positive association between all the independent variables and the dependent variable. These values suggest the verification of the hypotheses previously stated.

Table 5. Pearson and Spearman Correlation with the dependent variable PROP_NRes.

\begin{tabular}{lll}
\hline Dependent Variables & PROP_NRes. & \\
Independent Variables & Pearson & Spearman \\
\hline Agglomeration & $0.544^{\star \star \star}$ & $0.417^{\star \star \star}$ \\
University Institutions & $0.130^{\star \star}$ & $0.202^{\star \star \star}$ \\
Professional Institutions & $0.176^{\star \star \star}$ & $0.314^{\star \star \star}$ \\
R\&D Centres & $0.159^{\star \star}$ & 0.083 \\
Graduation Tourism & $0.232^{\star \star \star}$ & $0.206^{\star \star \star}$ \\
Masters Tourism & $0.255^{\star \star \star}$ & $0.243^{\star \star \star}$ \\
PhD Tourism & $0.203^{\star \star \star}$ & $0.211^{\star \star \star}$ \\
Professional Courses Tourism & $0.369^{\star \star \star}$ & $0.382^{\star \star \star}$ \\
\hline${ }^{\star \star \star} p<0.01 ; * p<0.05 ; * 0.1$ & &
\end{tabular}

The results for the MLR models of the dependent variable PROP_NRes are summarizes in Table 6. Model 1 indicates that agglomeration explains $70.2 \%$ of the variation in the proportion of international tourists. Including in this model knowledge variables (model 2), $72.1 \%$ of the variation in the proportion of international tourists is explained by independent variables, while model 3 explains $75.6 \%$, which suggests that knowledge resources are a relevant factor for attracting foreign tourists. Using the stepwise method to eliminate the statistically non-significant variables, for all models ( 1 to 3 ) the agglomeration presents a positive coefficient and are statistically significant, i.e., international tourists tend to be attracted to counties with a larger agglomeration of tourist firms, being verified $H 3$. 
Table 6. MLR model results for the dependent variable PROP_NRes.

\begin{tabular}{|c|c|c|c|c|c|}
\hline Independ. Var. & Model 1 & Model 2 & Model 2.1 & Model 3 & Model 3.1 \\
\hline Agglomeration & $22.085^{\star \star \star}$ & $19.996^{\star \star \star}$ & $20.066^{\star \star \star}$ & $19.355^{\star \star \star}$ & $19.320^{\star \star \star}$ \\
\hline University Institutions & & $1.913^{\star \star \star}$ & $2.148^{\star \star \star}$ & & \\
\hline Prof. Institutions & & $0.928^{\star \star \star}$ & $0.949 * \star \star$ & & \\
\hline R\&D Centres & & 6.193 & & -1.003 & \\
\hline Grad + Master & & & & 0.906 & \\
\hline PhD Tourism & & & & -0.841 & \\
\hline Professional Courses & & & & $4.882^{\star \star \star}$ & $5.508^{\star \star \star}$ \\
\hline$F$ & $576.014^{\star \star \star}$ & $158.418^{\star \star \star}$ & $210.710^{\star \star \star}$ & $151.072^{\star \star \star}$ & $379.277^{\star \star \star}$ \\
\hline $\mathrm{R}_{\mathrm{a}}{ }^{2}$ & 0.702 & 0.721 & 0.721 & 0.755 & 0.756 \\
\hline DW & 1.498 & 1.521 & 1.513 & 1.785 & 1.785 \\
\hline
\end{tabular}

Regarding the variables that measure knowledge, there is a positive relationship between university institutions and vocational training institutions in each county to attract international tourists, which leads to the verification of $H 4 a$ and $H 4 b$. Finally, with the introduction of the 4 proxy variables, there is a positive and statistically significant relationship between the professional courses offered in each county and attraction of international tourists, which leads to the verification of $H 4 b$. For all models, the Durbin-Watson indicator shows that residues are not correlated. Through the Kolmogorov-Smirnov test, it isn't verified the normal distribution of residual variable. In all models the absence of multicollinearity is verified. It is also observable the existence of 2 multivariate outliers in model 3.

\subsection{Counties Characterization}

The following graphical representations allow to identify the distribution of the variables under study and characterize the Portuguese counties, as well as to identify the similarities and disparities of growth and development of the regions.

Dependent variables. Fig. 1 shows that the decision to internationalize the hotel sector is not similar, and there are thus international growth disparities between the various counties. It is also possible to identify that the largest concentrations of internationalized hotels are in coastal areas or in large centres, possibly due to location advantages. In much of the Portuguese territory, there is also the absence of internationalized hotels or only one per county. 
Fig 1. Internationalized hotels relativized by 100.000 inhabitants
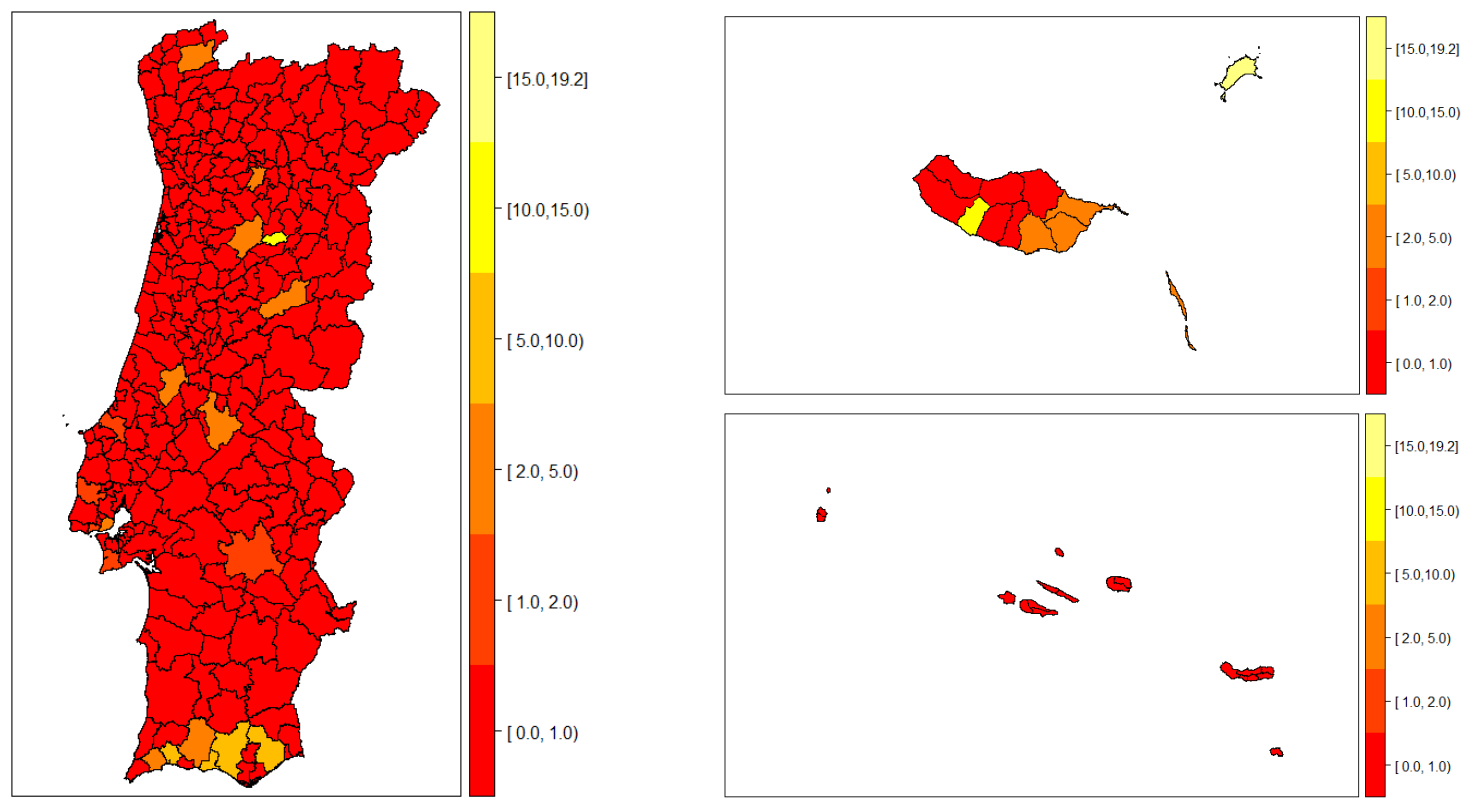

Regarding the proportion of international tourists (Fig. 2), these visit the different Portuguese counties annually, preferring instead the coastal locations, the large centres and islands for their stay. In turn, the interior regions have smaller tourist flows. It should be noted that this variable presents some confidentiality data, for the counties represented in white.

Fig 2. Proportion of international tourists
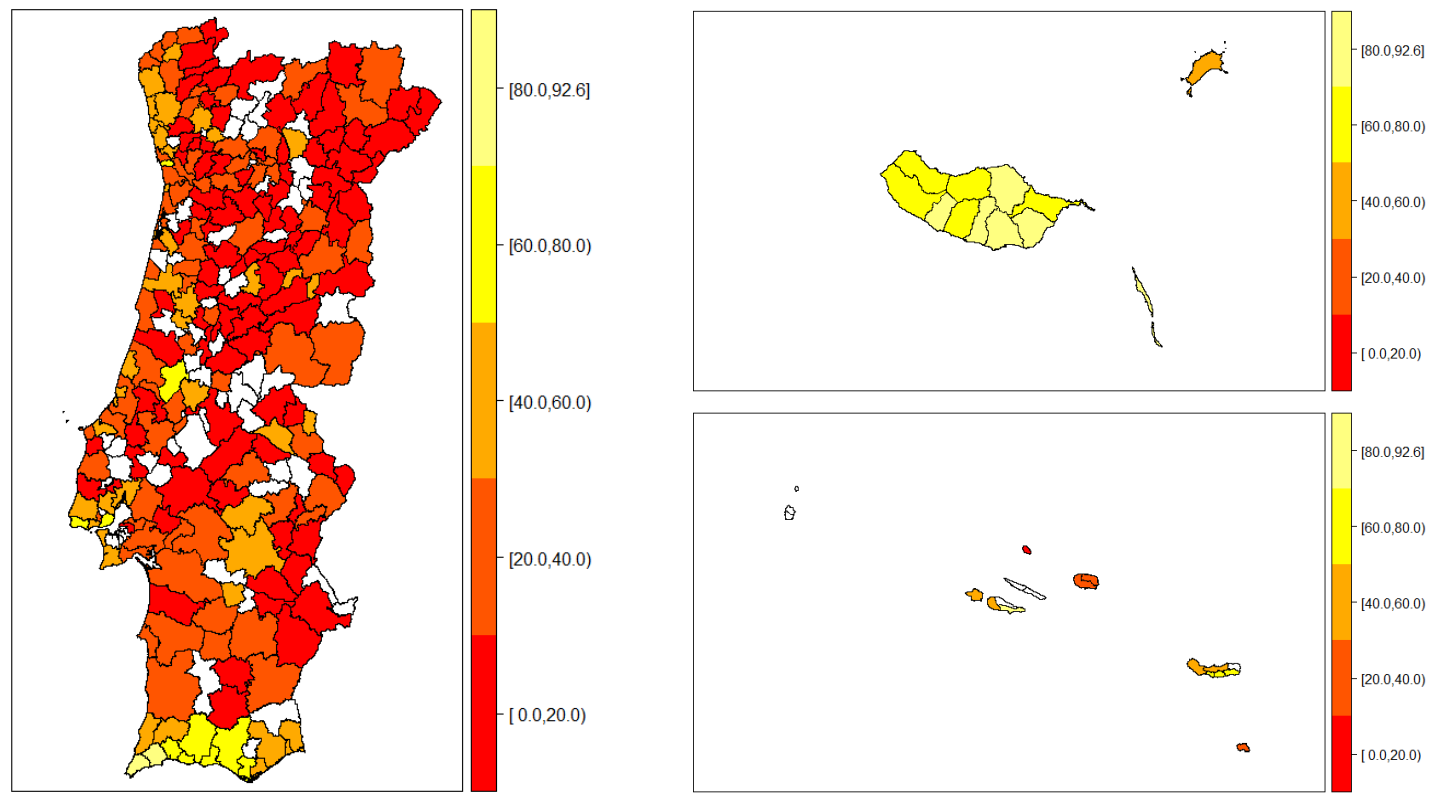

Independent variables. Regarding the degree of agglomeration of firms related to the tourism sector (Fig. 3), it is verified that their spatial distribution differs from region to region. This alternating pattern indicates that there is a significant concentration of tourism enterprises, with few regions where the degree of agglomeration is low. Comparing also the agglomeration with the internationalization of the hotels, it is verified that the regions with the highest concentration are 
those with a greater number of internationalized hotels and a greater flow of international tourists, as evidenced by the linear regression, which validated $H$ land $H 3$.

Fig 3. Degree of agglomeration of firms in the tourism sector
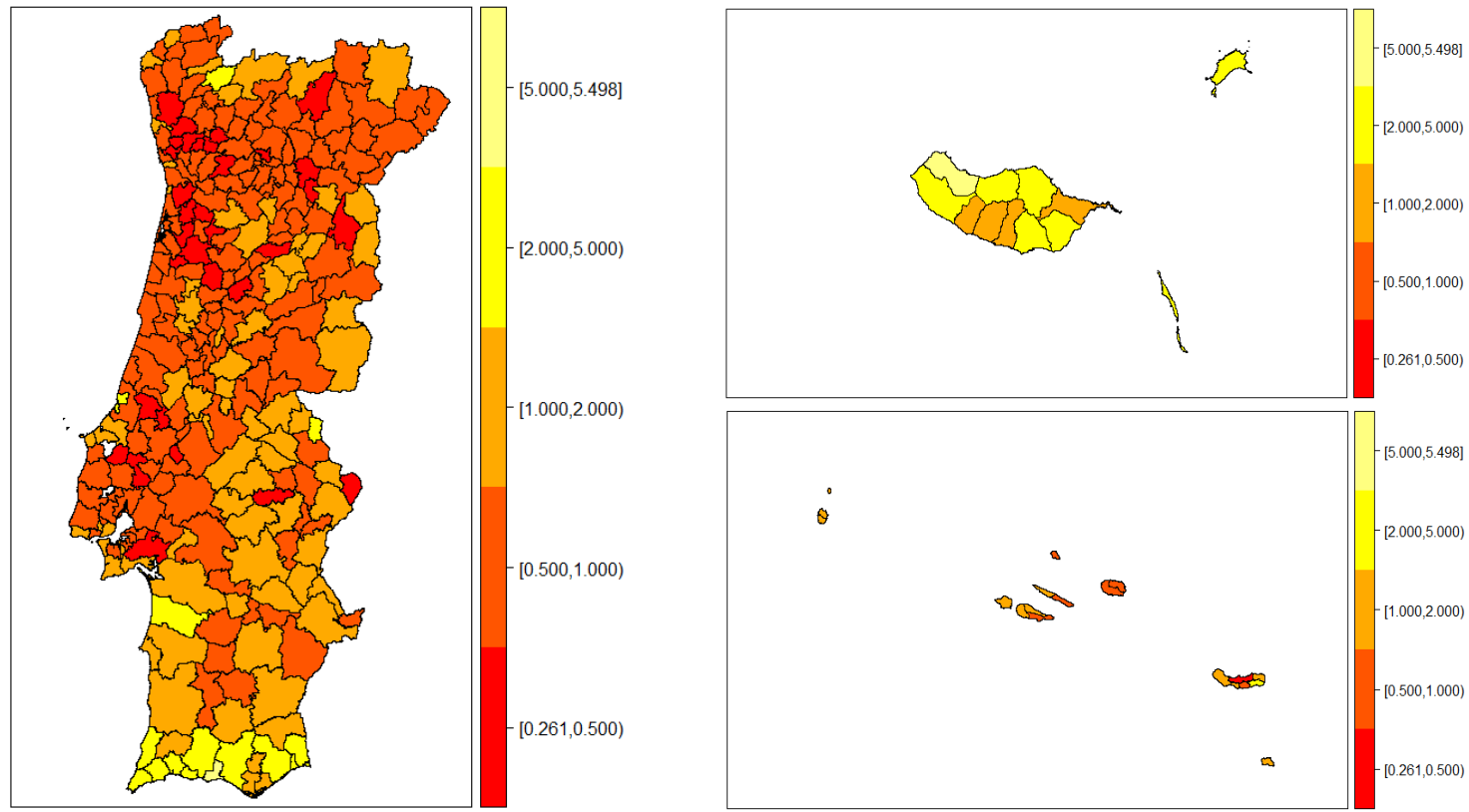

In terms of university institutions (Fig. 4), it is verified that in a large part of the Portuguese territory the investment in learning related to the tourism sector is null or only presents an educational institution with vocational courses. However, there are other regions that, possibly due to their centrality and because they receive a greater influx of tourists, have more university centres with tourism courses, what validates $\mathrm{H} 4 \mathrm{a}$. This variable is not statistically significant for the internationalization of hotels and the hypotheses $H 2 a$ is not validated.

Fig 4. University institutions relativized by 100.000 inhabitants
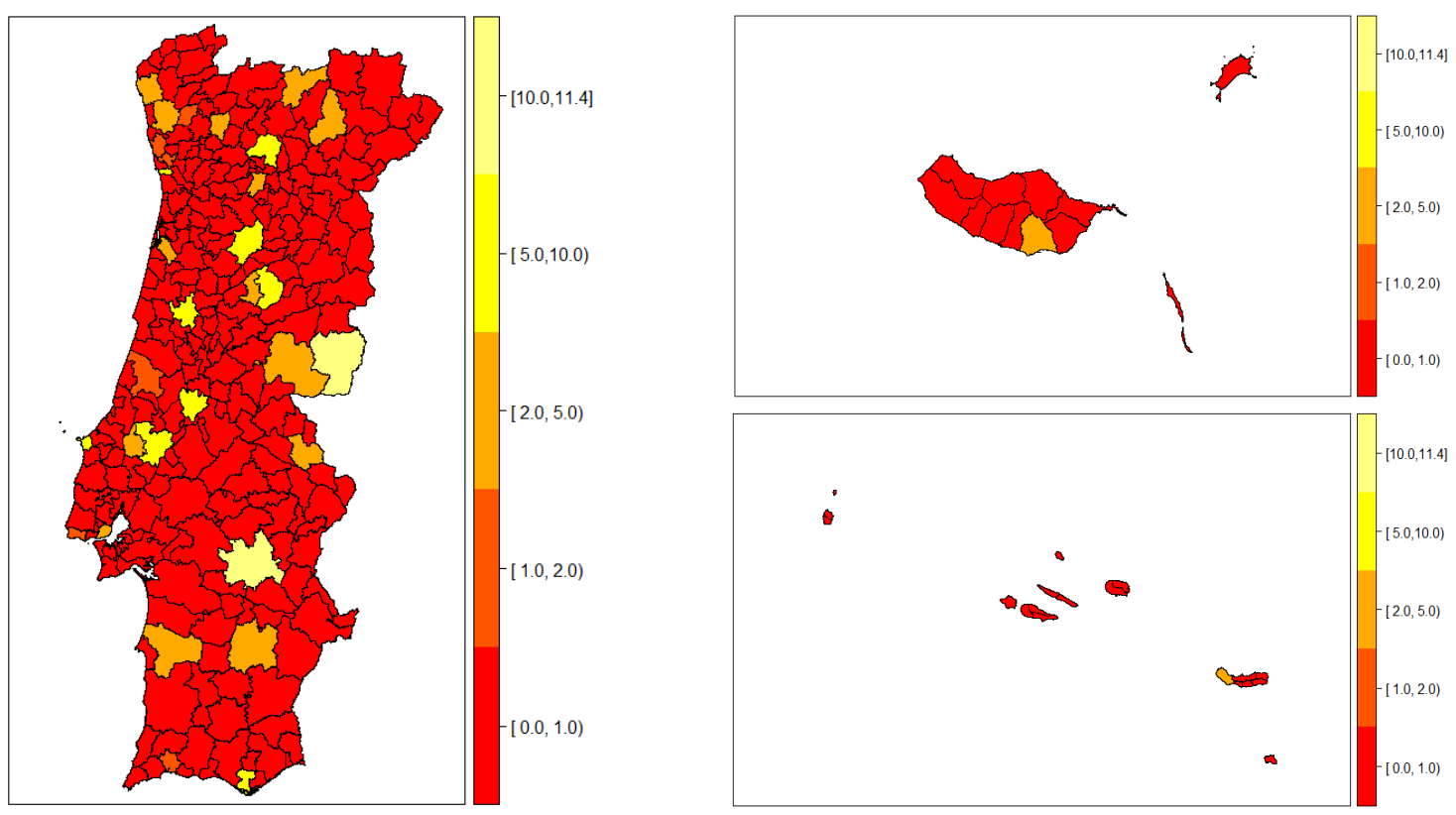
In turn, it is also verified that a large part of the Portuguese territory has a low number of vocational training centres or none (Fig. 5). However, it is visually evident that the counties that have the most specialized knowledge for the tourism sector are also those with internationalized hotels and a greater flow of international tourists, which validates $H 2 b$ and $H 4 b$.

Fig 5. Professional institutions relativized by 100.000 inhabitants
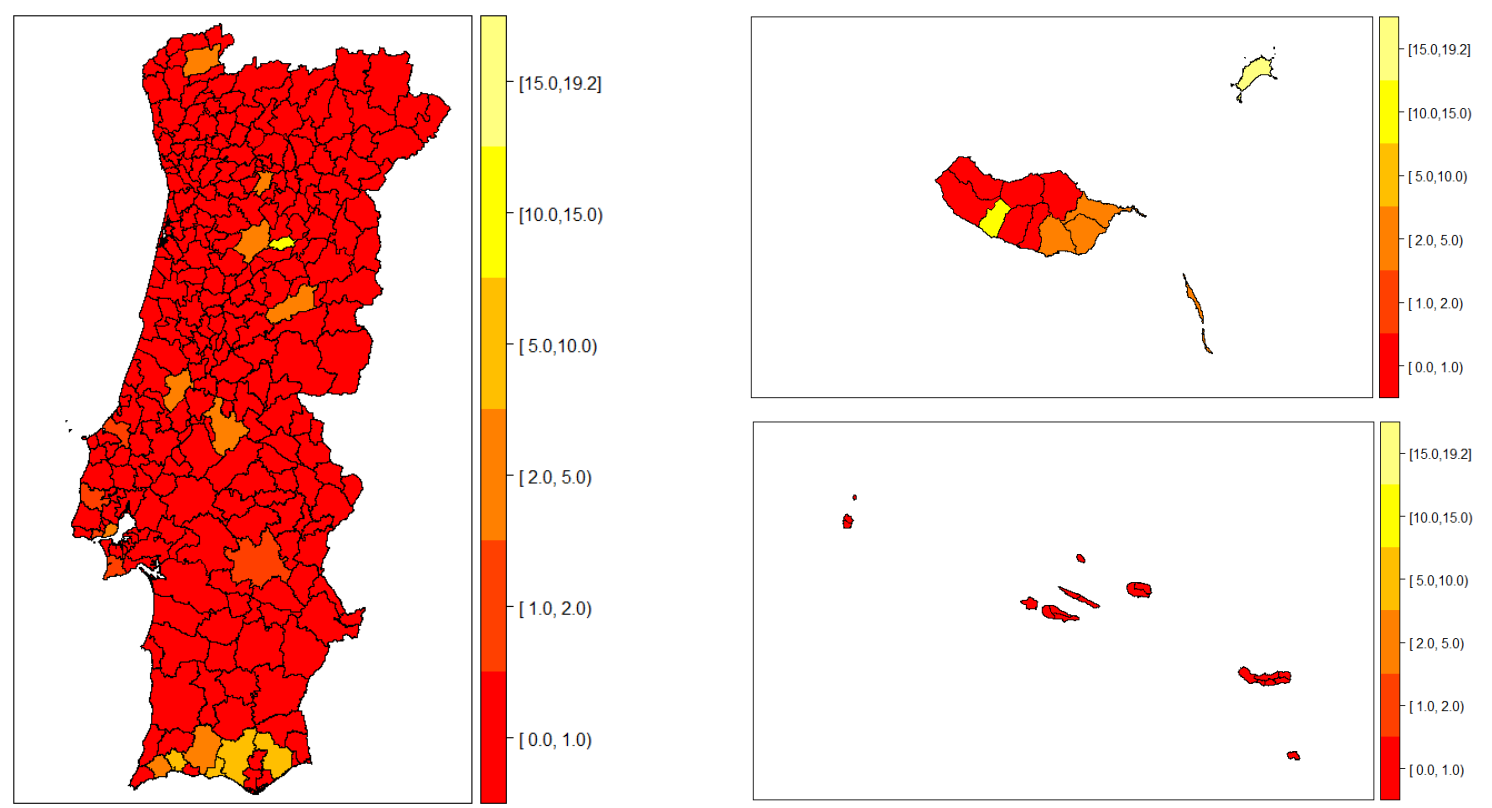

In terms of R\&D centres (Fig. 6), research investment in the tourism sector is weak, and there are still few dedicated centres in the country. This distribution indicates that the R\&D centres are not significant for the internationalization decision of the hotels nor for the attraction of international tourists. As in the linear regression, the non-verification of $H 2 C$ and $H 4 C$ is illustrative.

Fig 6. R\&D centres - public/private
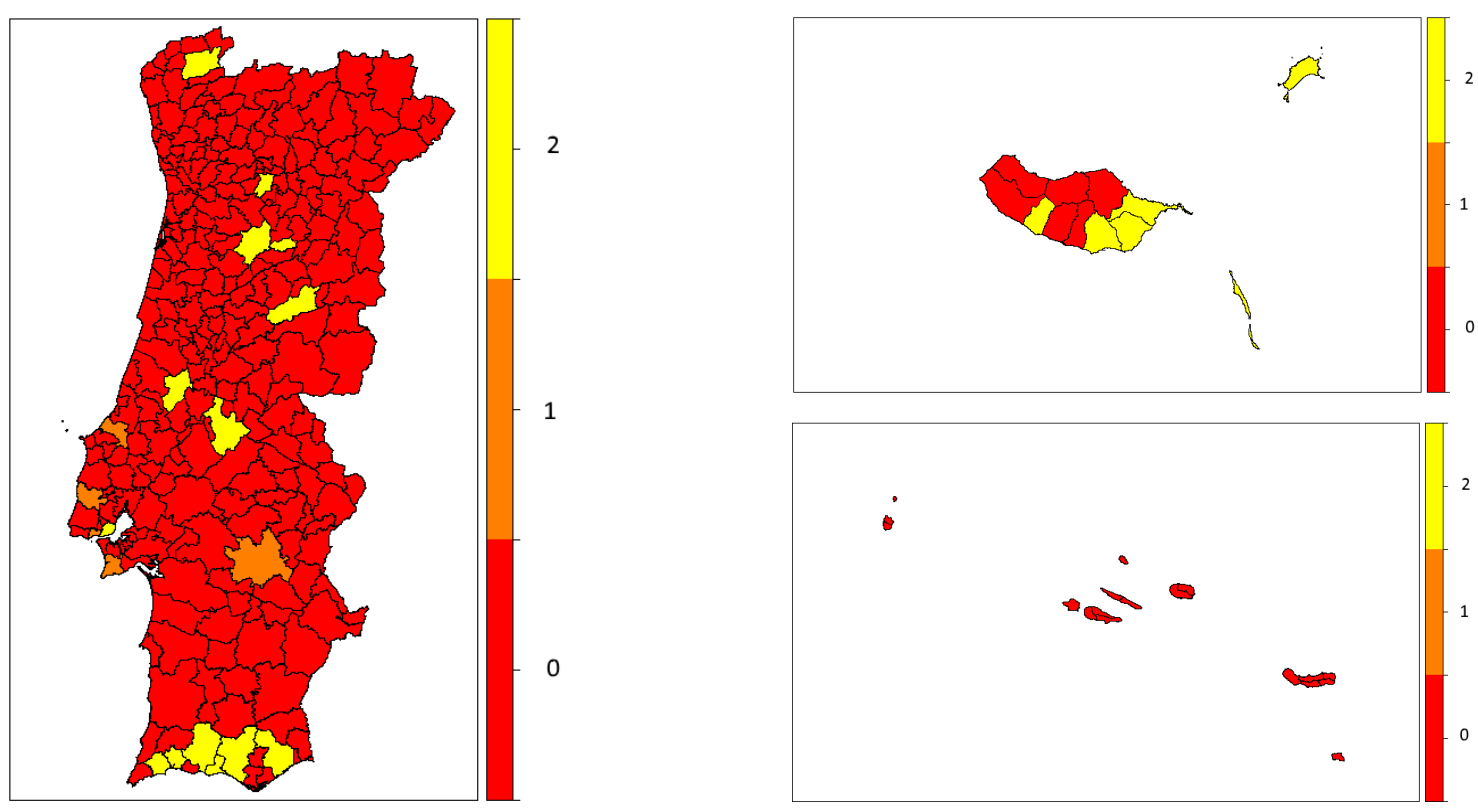
With the addition to the main model of the variable proxy number of degrees and masters related to the tourism sector (Fig. 7), it is verified that although there are more courses in certain locations these are not fundamental for the internationalization of the hotel chains nor for the attraction of international tourists.

Fig 7. Number of graduations and masters in tourism
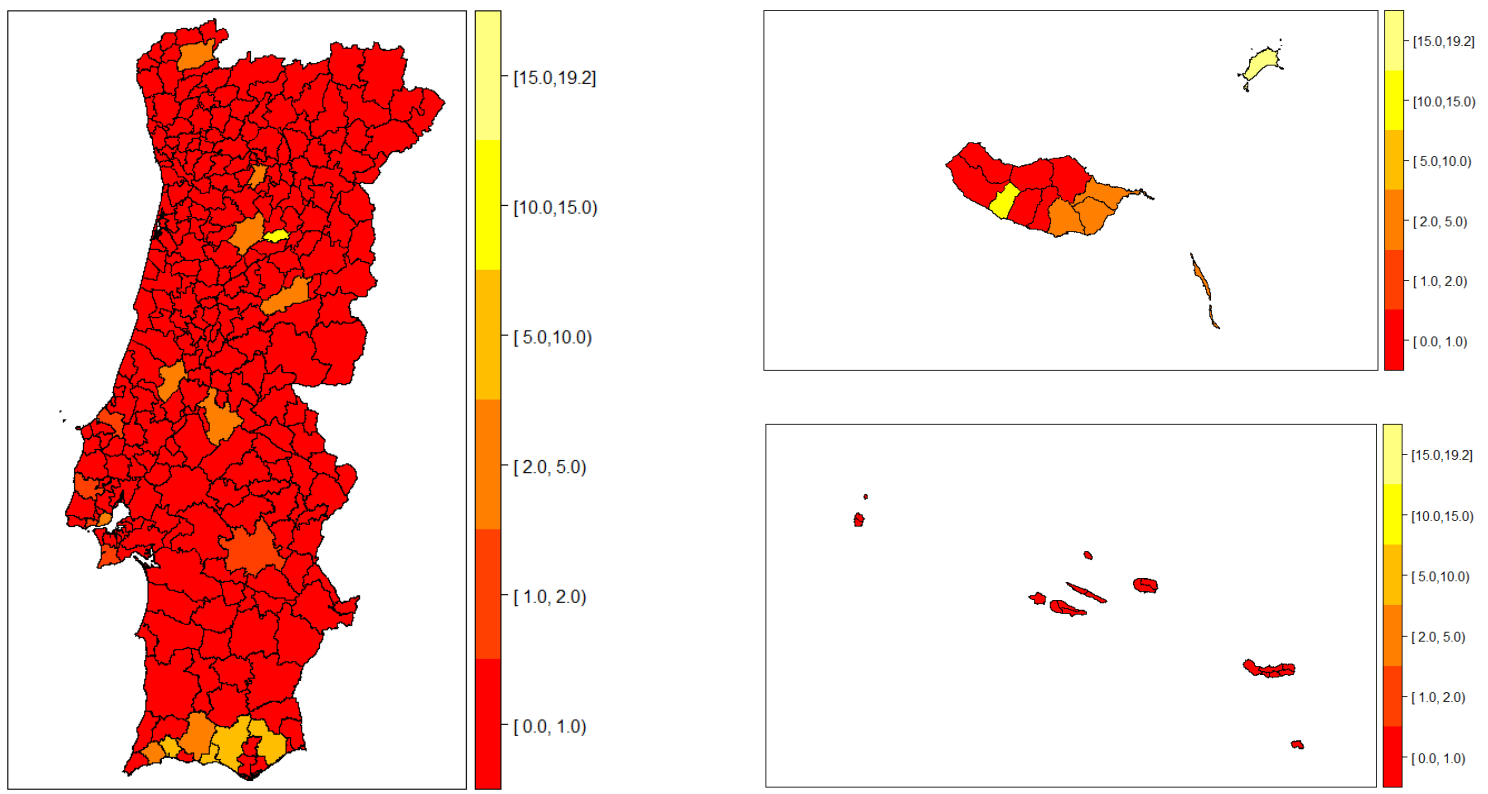

On the other hand, the offer of PhD (Fig. 8) is also reduced and grouped in only a few counties, reason why it is understood that they do not have significance for the internationalization of the hotels nor for the attraction of international tourists. These observations show, as in the linear regression, that, overall, a greater degree of academic supply is not significant for the sector, which leads to the non-verification of $\mathrm{H} 2 \mathrm{a}$ and $\mathrm{H} 4 \mathrm{a}$.

Fig 8. Number of PhD in tourism
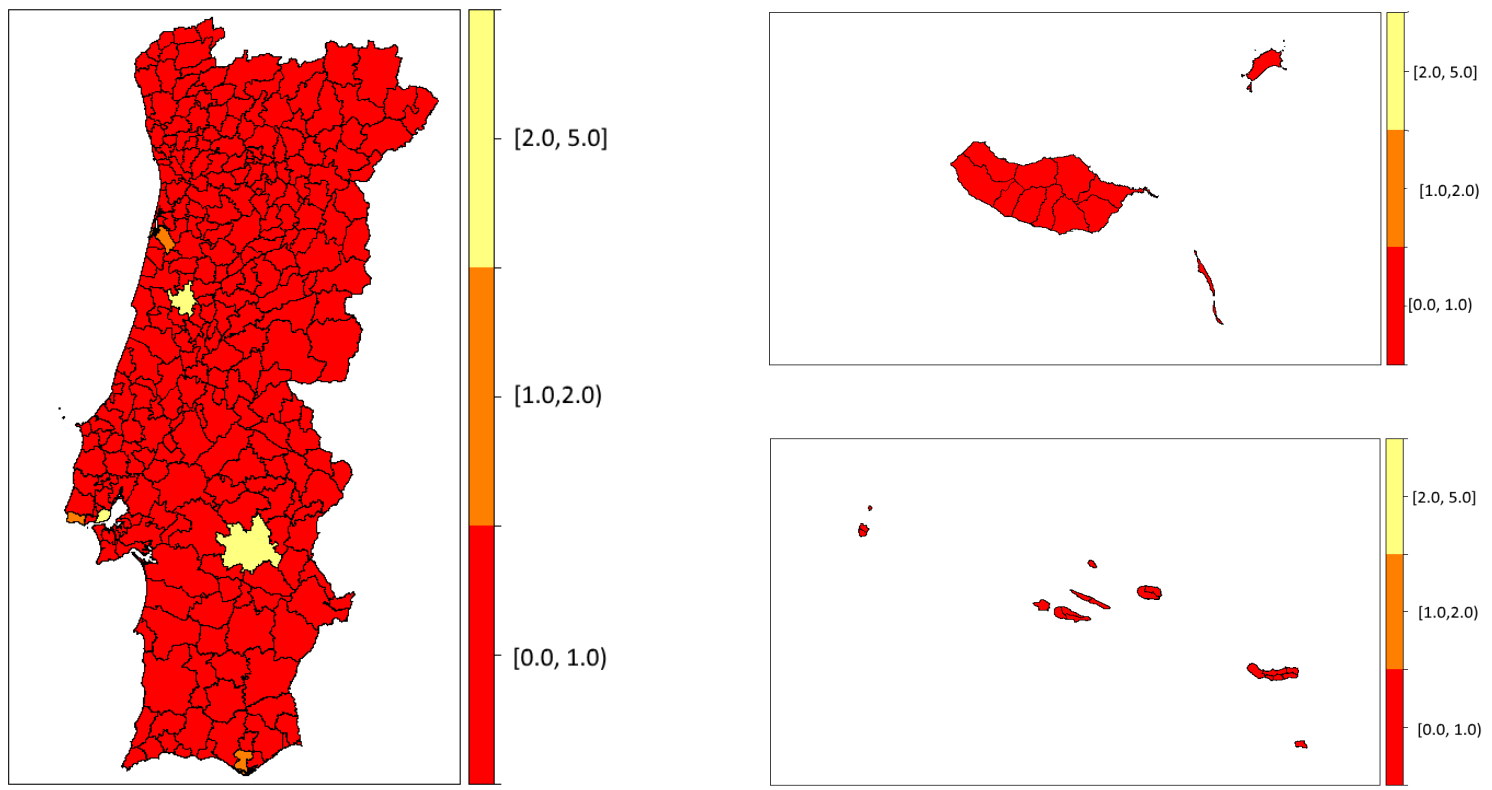
Regarding the professional courses (Fig. 9), it is verified, as for the number of professional training institutions, that the specific knowledge is significant in the process of internationalization and attraction of international tourists, which validates $H 2 b$ and $H 4 b$. This significance is due to the demand and offer of specialized tourism products/services.

Fig 9. Number of professional courses in tourism
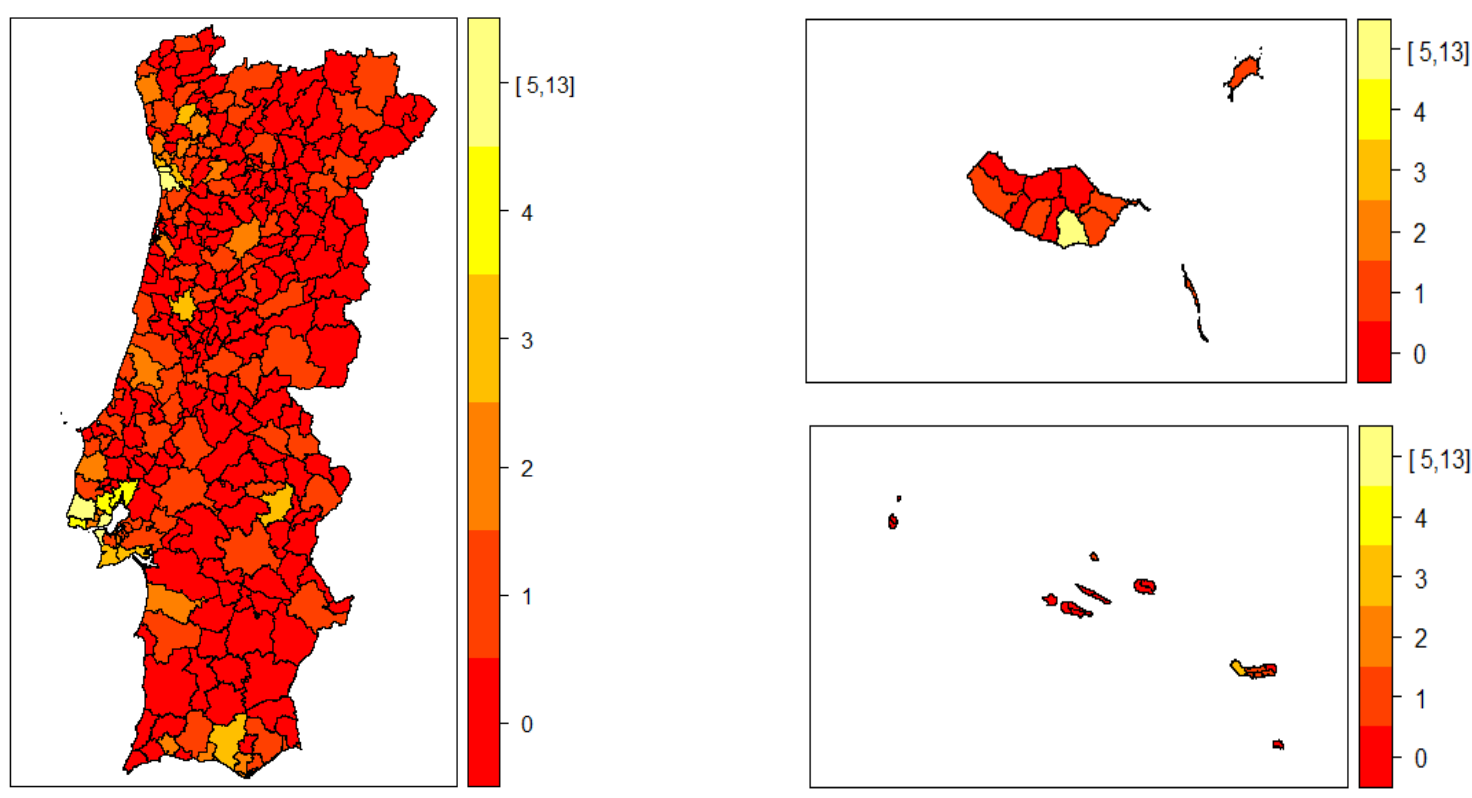

\section{Conclusions}

Considering the study of Marco-Lajara et al., (2017) for Spain and the study by NUTS III (Oliveira et al., 2019) and by counties for Portugal, it is verified that agglomeration largely explains the internationalization of the hotel chains, due to the positive externalities, such as the exchange of knowledge and resources and the establishment of beneficial connections for the development and geographic expansion. In turn, the agglomerations of firms related to the tourism sector also contribute to attract foreign tourists, as they tend to prefer to travel to places where there are many products/services that meet their needs.

Regarding knowledge, the literature refers that some resources are more relevant for the internationalization of the hotels and for the attraction of foreign tourists to the country. Thus, the investment in knowledge generated through university institutions and professional training contributes to attracting foreign tourists, due to the acquisition of general and specific knowledge inherent in the various tourism segments. On the other hand, Portuguese hotels consider that for internationalization they need specialized and qualified human resources, considering the continuous investment in vocational training to meet tourist demand and improve the quality of their services. 
It should be noted that innovation in the process leading to internationalization has played an important role in the development of skills and access to resources. These innovation inherent advantages provide firms in the tourism sector with the ability to present differentiated and attractive offers to current and potential customers, which translates into an increase in touristic flow.

In short, the combination of knowledge generated through educational institutions and the knowledge generated by firms within the clusters, through the experience in the market, actively contribute to the projection of horizons and objectives of expansion into new markets, but also to the attraction of tourists through a wide, diversified and qualified offer.

\section{References}

Aziri, B., Veseli, N., \& Ibraimi, S. (2013). Human Resources and Knowledge Management. Management, Knowledge and Learning, 19-21.

Baum, J. A., \& Haveman, H. A. (1997). Love thy neighbor? Differentiation and agglomeration in the Manhattan hotel industry, 1898-1990. Administrative Science Quarterly 42, 304-338.

Belhassen, Y., \& Caton, K. (2009). Advancing understandings: A linguistic approach to tourism epistemology. Annals of Tourism Research 36, 335-352.

Boschma, R. A., \& Wal, A. (2006). Knowledge Networks and Innovative Performance In An Industrial District: The Case of a Footwear District In The South of Italy. Papers in Evolutionary Economic Geography 06, 1-23.

Burger, M. J., Karreman, B., \& Eenennaam, F. v. (2015). The Competitive Advantage of Clusters: Cluster Organisations and Greenfield FDI in the European Life Sciences Industry. Geoforum 65 , 179-191.

Chaisumpunsakul, W., \& Pholphirul, P. (2018). Does International Trade Promote International Tourism Demand? Evidence From Thailand's Trading Partners. Kasetsart Journal of Social Sciences 39, 393-400.

Chambers, D., \& Buzinde, C. (2015). Tourism and decolonisation: Locating research and self. Annals of Tourism Research 51, 1-16.

Cooke, P., Uranga, M. G., \& Etxebarria, G. (1998). Regional systems of innovation: An evolutionary perspective. Environment and Planning 30, 1563-1584.

Cooper, C. (2006). Knowledge management and tourism. Annals of Tourism Research 33, 47-64.

Doloreux, D., \& Parto, S. (2005). Regional innovation systems: Current discourse and unresolved issues. Technology in Society 27, 133-153.

Eilat, Y., \& Einav, L. (2004). Determinants of international tourism: a threedimensional panel data analysis. Applied Economics 36, 1315-1327.

Farsani, N. T., Coelho, C. O., \& Costa, C. M. (2012). Analysis of Network Activities in Geoparks as Geotourism Destinations. International Journal of Tourism Research 16, 1-10. 
Freitas, C. C., \& Silva, Y. F. (2012). Conhecimento e capacitação do profissional no setor de turismo em Goiás. Revista Iberoamericana de Turismo 2, 108-118.

Gokovali, U., \& Avci, M. (2012). The role of human capital and collaboration with academia for innovation in hospitality sector: The case of Mugla. Revista de Turismo y Patrimonio Cultural 10, 7784.

Graitson, D. (1982). Spatial competition à la Hotelling: A selective survey. The Journal of Industrial Economics 31, 11-25.

Grissemann, U. S., Pikkemaat, B., \& Weger, C. (2013). Antecedents of innovation activities in tourism: An empirical investigation of the Alpine hospitality industry. Tourism 61, 7-27.

Hardy, A., Vorobjovas-Pinta, 0., \& Eccleston, R. (2018). Enhancing knowledge transfer in tourism: An elaborating likehood model approach. Journal of Hospitality and Tourism Management 37, 33-41.

Hershberger, S. L. (2003). The Growth Of Structural Equation Modeling: 1994-2001. Structural Equation Modeling: A Multidisciplinary Journal 10, 35-46.

Jaakson, R. (1996). Tourism In Transition In Post-Soviet Estonia. Annals of Tourism Research 23. 617-634.

Jesus, C., \& Franco, M. (2016). Cooperation networks in tourism: A study of hotels and rural tourism establishments in an inland region of Portugal. Journal of Hospitality and Tourism Management 29, 165-175.

Julião, L. d. (2013). Cidade, Cultura e Turismo: 0 impacto turístico em Guimarães, Capital Europeia da Cultura 2012. Escola Superior de Hotelaria e Turismo do Estoril, 1-100.

Kalnins, A., \& Chung, W. (2004). Resource-Seeking agglomeration: A study of market entry in the lodging industry. Strategic Management Journal 25, 689-699.

Kandampully, J., Bilgihan, A., \& Zhang, T. (2016). Developing a people-technology hybrids model to innovation and creativity: The new hospitality frontier. Journal of Hospitality and Tourism Management 29, 154-164.

Kline, R. B. (1998). Principles and Practice of Structural Equation Modeling. New York: Guilford Press.

Kofler, I., \& Marcher, A. (2018). Inter-organizational networks of small and medium-sized enterprises (SME) in the field of innovation: a case study of South Tyrol. Journal of Small Business \& Entrepreneurship 30, 9-25.

Kofler, I., Marcher, A., Volgger, M., \& Pechlaner, H. (2018). The special characteristics of tourism innovation networks: The case of the Regional Innovation System in South Tyrol. Journal of Hospitality and Tourism Management 37, 68-75.

López-Fernández, M. C., Serrano-Bedia, A. M., \& Gómez-López, R. (2011). Factors encouraging innovation in Spanish Hospitality Firms. Cornell Hospitality Quartely 52, 144-152.

Lundquist, K.-J., \& Winther, L. (2006). The Interspace Between Denmark and Sweden: The Industrial Dynamics of the Oresund Cross-Border Region. Journal of Geography, 115-129. 
Marco-Lajara, B., Zaragoza-Sáez, P. d., Claver-Cortés, E., Úbeda-García, M., \& García-Lillo, F. (2017). Tourist Districts And Internationalization Of Hotel Firms. Tourism Management 61, 451-464. Marshall, A. (1890). Principles of Economic. London: Macmillan.

Nguyen, T. D., Barrett, N. J., \& Fletcher, R. (2006). Information Internalisation and Internationalisation - Evidence From Vietnamese Firms. International Business Review 15, 682701.

Oliveira, A., Braga, V., \& Silva, E. C. (2019). Internationalization Strategies For Tourism In Portugal. Innovation, Engineering and Entrepreneurship. HELIX 2018. Lecture Notes In Electrical Engineering, vol 505. Springer, Cham, 978-984.

Papatheodorou, A. (2001). Why people travel to different places. Annals of Tourism Research 28, 164-179.

Simonceska, P. D. (2012). The changes and innovation as a factor of competitiveness od the tourist offer (The case of Ohrid). Procedia - Social and Behavioral Sciences 44, 32-43.

Travesi, C. (2017). The politics of knowledge as a tourist attraction. Annals of Tourism Research 66, 130-139.

Xiao, H., \& Smith, S. L. (2007). The use of tourism knowledge: Research propositions. Annals of Tourism Research 34, 310-331.

Yang, Y., Wong, K. K., \& Wang, T. (2012). How Do Hotels Choose Their Location? Evidence From Hotels In Beijing. International Journal of Hospitality Management 31, 675-685.

Zhou, L., Wu, W.-P., \& Luo, X. (2007). Internationalization and the Performance of Born-Global SMEs: The Mediating Role of Social Networks. Journal of International Business Studies 38, 673690. 


\section{Chapter IV \\ When Hotels go Abroad: The Internationalisation of the Portuguese Hospitality}




\title{
When Hotels go Abroad: The Internationalisation of the Portuguese Hospitality
}

\author{
Anabela Oliveira, Vítor Braga, and Eliana Costa e Silva \\ CIICESI, ESTG/P.PORTO - Centre for Innovation and Research in Business \\ Sciences and Systems Information, School of Technology and Management, \\ Polytechnic of Porto, Porto, Portugal \\ $\{8130100$, vbraga, eos\}@estg.ipp.pt
}

\begin{abstract}
The tourism sector in Portugal has been experiencing unequal levels of development in its different counties. These different regions display different natural, economic and social characteristics that impact on the internationalisation process and affect the attractiveness of foreign hotel chains. Supported by the existing literature, in this article, we present logistic models, based on data from 2015, to estimate the probability associated to the decision for internationalisation of the hotels' industry or to the establishment of foreign hotel chains in Portuguese territory. The logistic regression model concludes that the existence of a high degree of knowledge, access to inherited or developed resources and the participation on the international trade, affect the probability of internationalisation of hotels. In turn, the probability of foreign hotels establishing their activity in a certain region varies according to the international trade, the endowment of natural and historical-cultural resources and its climate.
\end{abstract}

Keywords: Internationalization - Tourism - Foreign Direct Investment - Logistic Regression - OLI Paradigm

\section{Introduction}

Over the last years, there has been a growing interest in the study of the determinants of international demand for tourism and the relationship between tourism's specialization and regional economic growth (Garin-Munoz et al., 2000; Chaisumpunsakul et al., 2017). In a global economy, tourism is of great importance for the development of countries, as the dynamism and high employment rate in the sector contributes to the development of the regions and promotes the country's image. Consequently, direct and indirect flows from tourism have a positive impact on other economic activities, such as catering, transport, accommodation, communications and other related services (Bozkurt et al. 2018; Kottaridi et al., 2017).

In territorial terms, tourism's demand can be heterogeneous and certain touristic destinations are more attractive to tourists and hotel chains, since they offer more complementary goods and services and a relative abundance of renewable resources (Rodríguez et al., 2012). Thus, tourism may promote local development; and more entrepreneurial regions with greater resources show stronger economic growth and investment.

By 2008 and onwards, the hotel industry was severely affected by the economic crisis, only recovering to full growth in 2014 , due to the reorganization of the sector and international economic growth. With a continuous dynamism, the tourism sector represents a considerable weight in the 
Portuguese economy, generating millions of euros, annually. For the Portuguese tourism market, 2015 was a year of investment due to the good performance of the hotel industry, the significant growth in the employment contribution, the growth in the number of overnight stays and the consumption levels of international tourists.

According to recent macroeconomic data, the tourism sector recorded in 2017, 57 million overnight stays generating revenues of approximately 2.5 million. The number of tourist enterprises increased, with hotels being the preferred touristic type, representing $73 \%$ of the offer and $68.7 \%$ of total overnight stays. In turn, this increase led to a more profitability use of assets and the return of $90 \%$ of tourists (Wakefield, 2017).

The increase in tourism demand, resulting from the hotel structure, the climate and the country's capacity to host, had a positive impact on the performance of the hospitality sector and the reduction of the unemployment rate, which consequently led to the growth of the economy (Moneris, 2017). In turn, the offer was reinforced by investing on new products/services and new experiences for the tourist (Deloitte, 2018).

This represents an alternative to exports, contributing for the payments' balance improvement and to strengthen the competitiveness of domestic firms. However, inequalities persist, and regions are willing to enjoy economic, social and environmental direct and indirect benefits from tourism.

From the dynamics of the hotel industry and the importance of the internationalization of the tourism sector, due to its business structure, consisting essentially of small and medium-sized firms, several studies have resulted (Marco-Lajara et al., 2017; Marco-Lajara et al., 2016; Chen, 2016) with the intention of ascertaining the macroeconomic determinants and resources that characterize the regions with the greatest competitiveness and economic development. The exploitation of international competitive advantages and the capture of hotel multinationals, due to the agglomeration economies of the industrial sector, which allow the establishment of links of cooperation and exchange of knowledge beneficial to the activity, allowed tourism tendentially of standardized mass to evolve to standards more individualistic, presenting greater flexibility and significant experiences (Hummelbrunner et al., 1994).

In this way, to deepen and identify indicators that directly or indirectly contribute to the penetration of hotel chains into new markets, the establishment of multinationals in Portuguese territory, as well as the capture of international tourists allows the recognition of the internal advantages that allow the affirmation of certain regions to the detriment of others, less driven by the touristic activities and the firms of complementary products.

Considering the above, and issues studied by the scientific literature related to the internationalization of tourism, this study aims to provide an overview of the internationalisation process of the Portuguese hotel chains. In a general way, our study aims to identify, both in national and regional terms, the determinants of the internationalization decision of the hotel industry or the establishment of foreign business investment and the contributions to the territorial development. On the other hand, the study aims to elucidate managers for the development of 
internationalisation strategies based on existing resources and inherent advantages, as well as if the choice of touristic destination can be affected by the motivations of specific groups of tourists or economic real estate valuation.

That way, this study aims to analyse at a local level: a) the role of knowledge, exogenous and macroeconomics variables in the decision process for internationalisation of the hotel chains; $b$ ) the role of knowledge, exogenous and macroeconomics variables in the decision to establish foreign hotel chains.

The rest of the paper is organized as followed: in section 2, a theoretical aproach is presented on the hotel internationalisation and on the attraction of foreign hotel investment in order to support the variables used in the study. Section 3 describes the methodology and the dataset. In section 4, the main results of the study are described. Finally, section 5 summarizes and presents the conclusions and perspectives for future research.

\section{Literature Review}

\subsection{Internationalisation of Hotels in Tourism Sector}

Although internationalisation is considered a process, it has been studied from a strategic point of view (Tuppura et al., 2008), to understand the mechanisms and reasons that drive firms to enter international markets (Game et al., 2016). According to the international business literature, in an increasingly competitive and globalized market, internationalisation can be an important requirement for the firm's development and success (Ciravegna et al., 2018), thus allowing the exploitation of competitive advantages and access to new business opportunities, available in a domestic market, so that firms can choose different routes of internationalisation (Alon, 2004), becoming international immediately or more gradually (Tuppura et al., 2008).

Businesses choosing faster and anticipated international commitment, i.e., when the period between the establishment in the domestic market and the entry into the foreign market is up to 3 years (Autio et al., 2000; McDougall et al., 2000), they are named 'Born Globals' (Knight et al., 2004; Oyna et al.,2018). These display distinct features of their counterparts operating in the domestic market that only gradually evolve in international markets (Johanson et al., 1977) motivated by the limitations or by the willingness to reduce the dependence of the domestic market or to achieve higher profit margins (Ciravegna et al., 2018).

For successful early internationalisation, entrepreneurial firms lacking tangible assets, develop their organizational capabilities based on knowledge resources and an innovative culture, to provide an optimized response to the markets and display a better performance in the business environment (Theodorakopoulos et. al, 2012). Considered as an important resource, the integration of specialized knowledge in the organization (Franco et al., 2016) is essential for gaining advantages that facilitate the entry and operations in external markets, thus creating value for customers (Knight et al., 2004). 
On the other hand, a more gradual or common international orientation, i.e. when the period between establishing in the domestic market and the entry into the foreign market is more than 3 years, firms internationalisation can be explained by: a) Resource-Based View, i.e. firms that tend to internationalize when they have internal or external competitive advantages, in terms of resources and skills (Matthew et al., 2007); b) Market-Based View i.e. internationalisation is influenced by constraints in the domestic market (Kamakura et al., 2012); c) entrepreneurship perspective, referring to the ability to perceive potential business opportunities and strategic decision-making in international expansion (Zahra et al., 2005; Kraus et al., 2018).

Commonly, this is the type of international entry most adopted by hotel chains, since it has a lower associated risk and the entrance in international markets (Alon et al., 2012) is determined by the level of market experience, versatility of resources, accumulation of knowledge and participation in networks (Knight et al., 2004). The accumulated know-how makes (Cohen et al.,1990) the internationalisation process easier for firms, as they gain knowledge faster, reduce the risk of imitation and identify new business opportunities more easily (Soriano et. al, 2014; Clavel et al., 2017). For the hotel industry, investment in specialized training is an important factor contributing to updating knowledge at both sectorial and internal levels, as well as the skills of management and employees (Rodríguez, 2002).

The concentration in specific geographical areas by firms in the same industry is considered a relevant factor in the internationalisation process. Such geographical co-location brings positive externalities for hotels, as well as access to knowledge resources and higher demand levels. Firms in agglomerations present competitive advantages and tend to internationalize (Wang et al., 2004) in order to exploit international opportunities.

However, the international development of the hotel industry and its competitiveness can also be affected by the characteristics of the market (Papadopoulos et al., 2010; Sozuer et al., 2017). Thus, the inclusion of economic measures in our study allows evaluating the dependence of international trade and the international performance of firms, exploring how export and import levels affect the international commitment and the level of internationalisation of hotels.

According to literature, regional factors provide value to the tourists (Wong et al., 2014; Cocklin et al., 1990), which are also important for the development of the region and its attraction. The hotel industry tends to locate in regions with access to resources, whether natural, historical-cultural or otherwise, that contradict the effects of seasonality. Gains in profitability and performance, provided by the access to exogenous factors, new opportunities and challenges arise hence fostering the internationalisation of hotels (Yang et al., 2016).

Market uncertainty and competitive pressure create on enterprises the need to incorporate into their corporate strategy entry into foreign markets and the execution of international transactions for accelerated growth. However, Portuguese hospitality rarely follows a radical pattern of internationalization, since the size affects the entry into external markets and most agents are small and medium enterprises (Nakos et al., 2002). These, generally, operate at a national level for a limited period of time due to financial and information limitations and only after obtaining all the 
necessary resources and assuring a sustainable competitive advantage (Grant, 2010) and significant profitability do they expand the business to new markets. During this process, hotels create networks of cooperation, external and regional partnerships and bet on standardization of processes and professionalization to increase their competitive advantages (Peters et al., 2005).

These advantages reduce uncertainty and the creation of synergies that promote knowledge transfer and improve entrepreneurial performance in terms of international activity. In this way, the Portuguese hotel chains, follow a model of transfer of advantages to the target market, in order to offer differentiated products/services and protect your resources and knowledge (Morschett et al., 2010).

\subsection{Foreign Hotels and Location Choice}

Foreign investments made by firms in other countries rather than their own is explained by the OLI paradigm, i.e. the decision to invest in foreign countries takes place when firms hold: a) ownership advantages, i.e. market power in terms of products / services or production processes; b) location advantages, i.e. benefits arising from the establishment of subsidiaries in foreign countries, which provide specific advantages in relation to the competition; and c) advantages of internalization i.e. advantages associated with the integration of intra-firm transactions (Burger et al. 2013; Majocchi et. al., 2016).

Market dynamism requires capabilities to attract foreign direct investment (FDI) to the country (Propis et al., 2006; Phelps, 2008), since multinationals provide access to valuable resources and skills as well as competitiveness, making the territory more attractive for investment (RodríguezClare, 2007). On the other hand, the attraction of both individual firms and investment poles (Solvell et al., 2003) plays a positive role in the development of the economy. Regions with the largest agglomeration of related firms display a more developed business environment and activities that facilitate the establishment of relationships between national and multinational firms, offering specialized services that may be attractive to the investment (Tomás-Miquel et.al., 2018), even though the economic agents involved in the process have different objectives (Burger et al., 2015).

Specific multinational holders seek to invest in countries where resources are abundant in regions benefiting from a knowledge based (Lattemann et al., 2015; Hsu et al., 2016). However, not all territories are appropriate for investment due to the lack of specialized location factors (Burger et al. 2013). In the process of attracting FDI, several factors are considered, for example, human capital (Cleeve, 2008), economic and political factors (Vijayakumar et al., 2010), institutions (Asiedu, 2006; Mohamed et al., 2010) and market resources to gain higher quality and lower cost assets when compared to the investor's country allowing meeting long-term strategic objectives and competitiveness.

Driven by globalization, the accumulation of knowledge and experience (Ferraris et. al, 2017), and the need for business diversification, the hotel industry is usually characterized by expanding 
into new geographic markets through direct investment. Regions with such conditions reach a competitive position in terms of tourism flows, given the opportunities and resources - natural, historical, leisure, as well as facilitated access to human resources, lower training costs and better-quality services provided (Carrasqueira, 2014).

Economic variables may also interfere with the foreign hotels decision to establish in a certain location, as they may influence interactions with markets and determine the intensity and level of internationalisation (Papadopoulos et al., 2010). Regions with higher levels of international trade and foreign investment display increased regional growth, allowing larger import and export of services (Mahmoodi, 2016; Alon et al, 2013).

Finally, when establishing in foreign territories, multinationals tend to prefer certain touristic destinations according to their characteristics. Thus, the climatic variables can affect the decision making in relation to the location of the facilities, as tourists may choose their destination based on the temperature of the touristic destination (Lyons et al., 2009).

\section{Methodology}

Previously applied by several studies in international hospitality (Barber et al., 2011; Rendón et al., 2014; Brida et al., 2015), the statistical technique of logistic regression estimates the probabilities between a binary dependent variable and a set of independent variables. The statistical software RStudio was used.

Data regarding the hotels in the 308 counties in Portugal, including the autonomous regions of Madeira and Azores, relative to the year 2015, were collected from the National Statistical Institute (INE - Instituto Nacional de Estatística). The dataset is composed of two qualitative variables (dependent variables) and 11 quantitative variables (independent variables).

Based on literature presented before, to estimate the probabilities associated with the internationalisation of Portuguese hotels or attraction of foreign hotels to the country, the statistical technique of logistic regression was applied, and the following two models were proposed:

$$
\begin{aligned}
& \log \left(\frac{\mu_{I}}{1-\mu_{I}}\right)=\beta_{0}+\beta_{1} \text { EXPORT }+\beta_{2} I M P O R T+\beta_{3} D G A G L O M \\
& +\beta_{4} \text { GRAD }+\beta_{5} \text { MASTR }+\beta_{6} \text { PhD }+\beta_{7} \text { PROFC }+\beta_{8} \text { HISTCULT } \\
& +\beta_{9} \text { PROT AREAS }+\beta_{10} \text { BATHWATER } \\
& e q(1) \\
& \log \left(\frac{\mu_{F}}{1-\mu_{F}}\right)=\beta_{0}+\beta_{1} E X P O R T+\beta_{2} I M P O R T+\beta_{3} D G A G L O M+\beta_{4} G R A D+\beta_{5} M A S T R+\beta_{6} P h D \\
& +\beta_{7} \text { PROFC }+\beta_{8} \text { HISTCULT }+\beta_{9} \text { PROT AREAS } \\
& +\beta_{10} \text { BATHWATER }+\beta_{11} \text { AIRTEMP }
\end{aligned}
$$

where,

- $\mu_{I}$ is the mean of the binary variable HOT_INT15_dummy which is coded as $1=$ Yes, if there are internationalized hotels in the country, or $0=$ No, otherwise; 
- $\mu_{F}$ is the mean of variable FORG_HOTI5_dummy which is coded as $1=$ Yes, if there are foreign hotels in the country, or $0=$ No, otherwise;

- EXPORT and IMPORT are total exports and imports of goods and services (in thousand euros per inhabitant). Data was collected from National Statistical Institute.

- DGAGLOM is the degree of agglomeration calculated as proposed by Oliveira et al., (2019) and Marco-Lajara et al. (2017), considering the employment of the tourism sector by counties and the total employment of the tourism sector in Portugal. Data on employment and unemployment in the country and for each county, corresponding to economic activity codes 55 and 56 - hotels, catering and tourism.

- GRAD, MASTR, PhD and PROFC - to measure the knowledge resources, the number of undergraduate degrees, masters, $\mathrm{PhD}$ and professional courses related to tourism sector, per 100000 inhabitants, was considered in each county, and all information was collected directly from Direção Geral de Estatística e Educação para a Ciência and Direção Geral dos Estabelecimentos Escolares.

- HISTCULT is the number of museums and monuments in each county. This variable intends to measure if the cultural heritage contribute to the probability of internationalisation of hotel chains. Data was collected from the Turismo de Portugal website.

- PROTAREAS is the number of protected areas in each county. This variable aims to measure if natural heritage sites contribute to the probability of internationalisation of hotel chains. Data was collected from the Turismo de Portugal website.

- BATHWATER is the number of bathing waters i.e. number of beaches in each county. This variable aims to verify if beaches contribute to the probability of internationalisation of hospitality, since it is a location advantage and a factor of attractiveness for tourists. Data was collected from the Turismo de Portugalwebsite.

- AIRTEMP is the air temperature, in each county. This variable is one of the main factors considered by tourists in their choice of the touristic destinations. It was included in order to assess the probability of foreign investment. Data was collected from National Statistical Institute.

\section{Results and Discussion}

\subsection{Internationalized Hotels}

Table 1 shows the medians, means and standard deviations of each variable and for the two groups defined the HOT_INT15_dummy $(1=$ Yes, if there are internationalized hotels in the country, or $0=$ No, otherwise). To verify the assumption of normality, the Kolmogorov-Smirnov test was applied and since the sample does not assume normality and the variances are different, the non-parametric Mann-Whitney-Wilcoxon test was used to compare the medians of each variable according to the groups defined by the variable HOT_INT15_dummy. Since data does not display normality, the non- 
parametric Spearman correlation test was used to study the correlation between the dependent variable and each of the independent variables, which shows the existence of a possible positive association between all the independent variables and the dependent variable.

Table 1: Median, mean, standard deviation and Mann-Whitney-Wilcoxon test for two groups defined according the variable HOT_INT15_dummy

\begin{tabular}{|c|c|c|c|c|c|}
\hline Variables & $\begin{array}{c}\text { All cases } \\
\text { Median/ } \\
\text { Mean } \\
\text { (Std. Deviation) }\end{array}$ & $\begin{array}{c}\text { HOT_INT15 } \\
0(\text { No) } \\
\text { Median/ } \\
\text { Mean } \\
\text { (Std. Deviation) }\end{array}$ & $\begin{array}{c}\text { HOT_INT15 } \\
1 \text { (Yes) } \\
\text { Median/ } \\
\text { Mean } \\
\text { (Std. Deviation) }\end{array}$ & $\begin{array}{l}\text { p-value } \\
\text { Mann- } \\
\text { Whitney- } \\
\text { Wilcoxon } \\
\text { test }\end{array}$ & Correlation \\
\hline EXPORT & $\begin{array}{c}0.9189 / \\
3.3572 \\
(6.63)\end{array}$ & $\begin{array}{c}0.9507 / \\
3.4539 \\
(6.88)\end{array}$ & $\begin{array}{c}0.8714 / \\
2.4609 \\
(3.50)\end{array}$ & 0.9389 & $0.0036^{\star \star \star \star}$ \\
\hline IMPORT & $\begin{array}{l}0.8679 / \\
2.5069 \\
(4.78)\end{array}$ & $\begin{array}{c}0.8295 / \\
2.3665 \\
(4.28)\end{array}$ & $\begin{array}{c}1.1128 / \\
3.8073 \\
(8.10)\end{array}$ & 0.2541 & $0.0533^{*}$ \\
\hline DGAGLOM & $\begin{array}{c}0.8815 / \\
650.4095 \\
(8044.93)\end{array}$ & $\begin{array}{c}0.8515 / \\
720.4062 \\
(8466.40)\end{array}$ & $\begin{array}{c}1.3009 / \\
1.7737 \\
(1.15)\end{array}$ & $1.3 e-06^{\star \star \star}$ & $0.2256^{\star \star \star}$ \\
\hline GRAD & $\begin{array}{c}0.0000 / \\
0.4320 \\
(1.59)\end{array}$ & $\begin{array}{c}0.0000 / \\
0.3522 \\
(1.51)\end{array}$ & $\begin{array}{c}0.0000 / \\
1.1709 \\
(2.13)\end{array}$ & $4.0 e-04^{\star \star \star}$ & $0.1967^{\star \star \star}$ \\
\hline MASTR & $\begin{array}{c}0.0000 / \\
0.2280 \\
(1.11)\end{array}$ & $\begin{array}{l}0.000 / \\
0.1751 \\
(1.04)\end{array}$ & $\begin{array}{c}0.000 / \\
0.7184 \\
(1.57)\end{array}$ & $2.6 \mathrm{e}-04^{\star \star \star}$ & $0.2051^{\star \star \star}$ \\
\hline PhD & $\begin{array}{l}0.000 / \\
0.0311 \\
(0.26)\end{array}$ & $\begin{array}{c}0.0000 / \\
0.0106 \\
(0.13)\end{array}$ & $\begin{array}{c}0.0000 / \\
0.2217 \\
(0.73)\end{array}$ & $2.3 e-06^{\star \star \star}$ & $0.2690^{\star * \star}$ \\
\hline PROFC & $\begin{array}{l}0.000 / \\
1.8433 \\
(3.92)\end{array}$ & $\begin{array}{l}0.0000 / \\
1.718 \\
(3.93)\end{array}$ & $\begin{array}{c}2.1302 / \\
3.0032 \\
(3.68)\end{array}$ & $4.8 e-06^{\star \star \star}$ & $0.2384^{\star \star \star}$ \\
\hline HISTCULT & $\begin{array}{c}2.0000 / \\
4.0455 \\
(6.28)\end{array}$ & $\begin{array}{c}2.0000 / \\
3.2374 \\
(3.53)\end{array}$ & $\begin{array}{c}9.0000 / \\
11.5333 \\
(15.31)\end{array}$ & $1.8 \mathrm{e}-07^{\star \star \star}$ & $0.2573^{\star \star \star}$ \\
\hline PROTAREAS & $\begin{array}{l}0.0000 / \\
0.3247 \\
(0.60)\end{array}$ & $\begin{array}{l}0.0000 / \\
0.2734 \\
(0.52)\end{array}$ & $\begin{array}{c}0.5000 / \\
0.8000 \\
(0.9965458)\end{array}$ & $5.4 e-04^{\star \star \star}$ & $0.1935^{\star \star \star}$ \\
\hline BATHWATER & $\begin{array}{c}0.0000 / \\
1.8474 \\
(3.4376)\end{array}$ & $\begin{array}{l}0.0000 / \\
1.5252 \\
(3.00)\end{array}$ & $\begin{array}{c}4.0000 / \\
4.8333 \\
(5.39)\end{array}$ & $1.1 e-06^{\star \star \star}$ & $0.2542^{\star \star \star}$ \\
\hline
\end{tabular}

${ }^{*} p<0.10 ;{ }^{\star \star} p<0.05 ;{ }^{\star \star \star} p<0.01$

According to the non-parametric Mann-Whitney-Wilcoxon test, at a significance level of $5 \%$, the null hypothesis is rejected for all variables, except for EXPORT and IMPORT. Therefore, for the majority of the variables there are significant differences between counties with and without 
internationalized hotels. This suggests that the variables EXPORTand IMPORTare not relevant to explaining the variable HOT_INT15_dummyin the logistic regression model.

The summary of the logit model (eq.1), presented in table 2, indicates that only some of the variables suggested by the previous analysis to the literature are significant for the model: EXPORT, IMPORT, MASTR; PhD, HISTCULT, PROTAREAS and BATHWATER. On the other hand, the variables EXPORT and IMPORT were not suggested by the explanatory analysis to be relevant, however they are significant for the logit model.

Table 2: Summary of logit model in Equation 1

\begin{tabular}{|c|c|c|c|c|c|}
\hline $\begin{array}{l}\text { Independent } \\
\text { Variables }\end{array}$ & Estimate & Std. Error & $z$ value & $\mathrm{p}$-value & $\exp ($ beta_i) \\
\hline (INTERCEPT) & $-4.546 e+00$ & $5.669 e-01$ & -8.019 & $1.06 \mathrm{e}-15^{\star \star \star}$ & 0.01 \\
\hline EXPORT & $-2.366 e-01$ & $1.127 e-01$ & -2.100 & 0.0357 * & 0.79 \\
\hline IMPORT & $1.144 \mathrm{e}-01$ & $6.197 e-02$ & 1.846 & 0.0648 * & 1.12 \\
\hline DGAGLOM & $-6.678 e-05$ & $1.350 \mathrm{e}-03$ & -0.049 & 0.9605 & 1.00 \\
\hline GRAD & $7.300 \mathrm{e}-02$ & $1.343 e-01$ & 0.543 & 0.5867 & 1.08 \\
\hline MASTR & $-6.244 e-01$ & $3.736 e-01$ & -1.671 & 0.0946 * & 0.54 \\
\hline $\mathrm{PhD}$ & $1.602 e+00$ & $8.726 e-01$ & 1.836 & 0.0664 * & 4.96 \\
\hline PROFC & $3.992 e-02$ & $5.627 e-02$ & 0.709 & 0.4780 & 1.04 \\
\hline HISTCULT & $2.500 e-01$ & $5.825 e-02$ & 4.291 & $1.78 \mathrm{e}-05^{* \star *}$ & 1.28 \\
\hline PROTAREAS & $1.316 e+00$ & $3.331 e-01$ & 3.950 & $7.81 e-05^{\star \star \star}$ & 3.73 \\
\hline BATHWATER & $1.337 e-01$ & $4.925 e-02$ & 2.715 & $0.0066^{* *}$ & 1.14 \\
\hline Null deviance & \multicolumn{5}{|c|}{196.71 on 307 degrees of freedom } \\
\hline Residual deviance & \multicolumn{5}{|c|}{121.67 on 297 degrees of freedom } \\
\hline AIC & \multicolumn{5}{|c|}{143.67} \\
\hline
\end{tabular}

To verify the validity of the model, several statistical tests and assumptions were validated. The Hosmer-Lemeshow test was applied to test the goodness of the model. The null hypothesis of this test is:

HO: the model is correctly adjusted to the data.

The Hosmer-Lemeshow statistical test is $X^{2}=4.6634$, with 8 degrees of freedom and a $p$-value of 0.7929 . Therefore, for a significance level of 0.05 the null hypothesis is not rejected, hence the model is correctly adjusted to the data. In turn, the likelihood ratio test presents a p-value of 0.56 , with 11 degrees of freedom.

The mean of Pearson's residuals, is near zero (0.0137) and the variance is small (1), showing that the model is valid.

Figure 1 indicates that some outliers are present for the deviance residuals, but only 8 observations have a residual deviation above 2 . As most of the residues are between -2 and 2 , the model is considered as adjusted. 
Fig 1: Fitted values and index vs. residual deviance
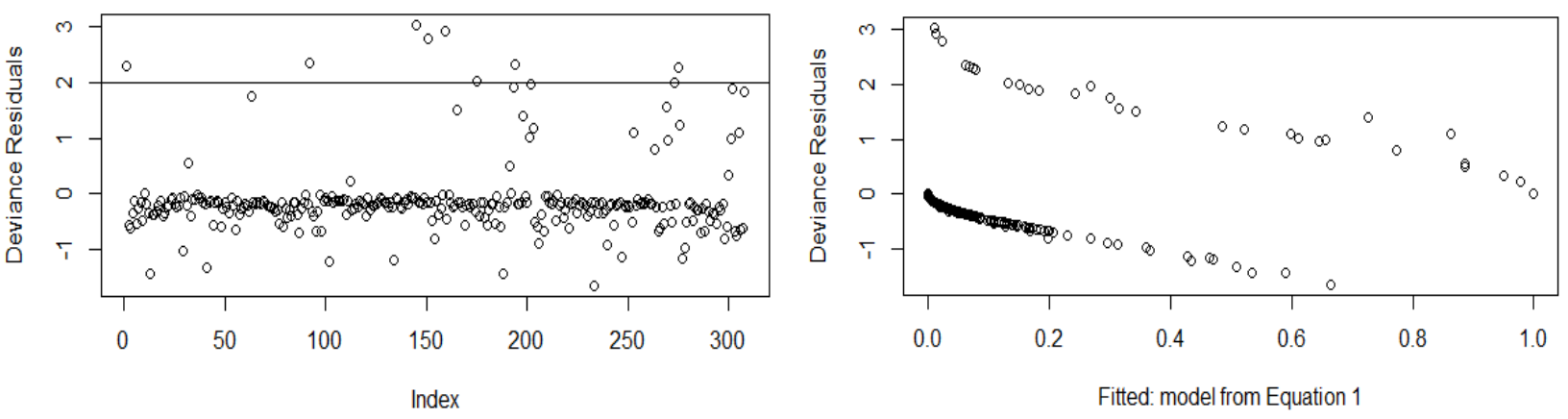

\subsection{Foreign Hotels}

The table 3 shows the medians, means and standard deviations for each variable according to the FORG_HOT15_dummy ( $1=$ Yes, if there are foreign hotels in the country, or $0=0$ therwise). To verify the assumption of normality, the Kolmogorov-Smirnov test was applied and since the data does not display normality and the variances are different, the non-parametric Mann-WhitneyWilcoxon test was used to compare the medians of each variable according to the groups defined by the variable FORG_HOT15_dummy. The correlation test shows the existence of a possible positive association between all the independent variables and the dependent variable.

Table 3: Median, mean, standard deviation and Mann-Whitney-Wilcoxon test for two groups defined according the variable FORG_HOT15_dummy

\begin{tabular}{|c|c|c|c|c|c|}
\hline Variables & $\begin{array}{l}\text { All cases } \\
\text { Median/ } \\
\text { Mean } \\
\text { (Std. Deviation) }\end{array}$ & $\begin{array}{c}\text { FORG_HOT15 } \\
\text { O(No) } \\
\text { Median/ } \\
\text { Mean } \\
\text { (Std. } \\
\text { Deviation) }\end{array}$ & $\begin{array}{c}\text { FORG_H0T151 } \\
\text { (Yes) } \\
\text { Median/ } \\
\text { Mean } \\
\text { (Std. Deviation) }\end{array}$ & $\begin{array}{c}\text { p-value } \\
\text { Mann- } \\
\text { Whitney- } \\
\text { Wilcoxon } \\
\text { test }\end{array}$ & Correlation \\
\hline EXPORT & $\begin{array}{l}0.9189 / \\
3.3572 \\
(6.63)\end{array}$ & $\begin{array}{c}0.8315 / \\
3.1796 \\
(6.97)\end{array}$ & $\begin{array}{l}3.4759 / \\
4.2316 \\
(4.52)\end{array}$ & $2.2 \mathrm{e}-04^{\star \star \star}$ & $0.1725^{\star \star \star}$ \\
\hline IMPORT & $\begin{array}{l}0.8679 / \\
2.5066 \\
(4.78)\end{array}$ & $\begin{array}{l}0.6861 / \\
2.0861 \\
(4.24)\end{array}$ & $\begin{array}{c}2.7989 / \\
4.5784 \\
(6.52)\end{array}$ & $7.8 \mathrm{e}-08^{\star \star \star}$ & $0.2509^{\star \star \star}$ \\
\hline DGAGLOM & $\begin{array}{c}0.8815 / \\
650.4095 \\
(8044.93)\end{array}$ & $\begin{array}{c}0.8761 / \\
782.2356 \\
(8821.31)\end{array}$ & $\begin{array}{c}0.9660 / \\
1.4197 \\
(1.19)\end{array}$ & $9.0 e-02^{*}$ & $0.0792^{\star}$ \\
\hline GRAD & $\begin{array}{c}0.0000 / \\
0.4320 \\
(1.59)\end{array}$ & $\begin{array}{c}0.0000 / \\
0.3174 \\
(1.42)\end{array}$ & $\begin{array}{c}0.0000 / \\
0.9959 \\
(2.18)\end{array}$ & $1.4 \mathrm{e}-06^{\star \star \star}$ & $0.2683^{\star \star \star}$ \\
\hline MASTR & $\begin{array}{c}0.0000 / \\
0.2280 \\
(1.11)\end{array}$ & $\begin{array}{c}0.0000 / \\
0.0964 \\
(0.66)\end{array}$ & $\begin{array}{c}0.0000 / \\
0.8764 \\
(2.17)\end{array}$ & $4.1 \mathrm{e}-08^{\star \star \star}$ & $0.3079 * * \star$ \\
\hline PhD & $\begin{array}{c}0.0000 / \\
0.0311\end{array}$ & $\begin{array}{l}0.0000 / \\
0.0000\end{array}$ & $\begin{array}{c}0.0000 / \\
0.1843\end{array}$ & $4.4 \mathrm{e}-08^{\star \star \star}$ & $0.3115^{\star \star \star}$ \\
\hline
\end{tabular}




\begin{tabular}{|c|c|c|c|c|c|}
\hline & $(0.26)$ & $(0.00)$ & $(0.62)$ & & \\
\hline \multirow[t]{3}{*}{ PROFC } & $0.0000 /$ & $0.0000 /$ & $1.8845 /$ & $4.9 e-07^{\star \star \star}$ & $0.2621^{\star \star \star}$ \\
\hline & 1.8433 & 1.7891 & 2.1101 & & \\
\hline & $(3.92)$ & $(4.21)$ & $(1.88)$ & & \\
\hline \multirow[t]{3}{*}{ HISTCULT } & $2.0000 /$ & $2.0000 /$ & $9.0000 /$ & $1.1 e-12^{\star \star \star}$ & $0.3507^{\star \star \star}$ \\
\hline & 4.0455 & 2.8125 & 10.1154 & & \\
\hline & $(6.28)$ & $(2.86)$ & $(12.30)$ & & \\
\hline \multirow[t]{3}{*}{ PROTAREAS } & $0.0000 /$ & $0.0000 /$ & $0.0000 /$ & $1.3 e-01$ & $0.0852^{*}$ \\
\hline & 0.3247 & 0.3008 & 0.4423 & & \\
\hline & $(0.60)$ & $(0.58)$ & $(0.70)$ & & \\
\hline \multirow[t]{3}{*}{ BATHWATER } & $0.0000 /$ & $0.0000 /$ & $2.0000 /$ & $7.5 e-06^{\star \star \star}$ & $0.2333^{\star \star \star}$ \\
\hline & 1.8474 & 1.2383 & 4.8462 & & \\
\hline & $(3.44)$ & $(2.11)$ & $(6.14)$ & & \\
\hline \multirow[t]{3}{*}{ AIRTEMP } & $16.3 /$ & $16.3 /$ & $16.2 /$ & $9.7 e-01$ & $0.0015^{\star \star}$ \\
\hline & 111.6649 & 127.2262 & 35.0558 & & \\
\hline & (291.97) & $(312.21)$ & $(136.30)$ & & \\
\hline
\end{tabular}

* $p<0.10 ;{ }^{\star \star} p<0.05 ; * \star \star * * 0.01$

According to the non-parametric Mann-Whitney-Wilcoxon test, at a significance level of $5 \%$, the null hypothesis is rejected for all variables except for PROTAREAS and AIRTEMP. For a significance of $10 \%$ the null hypothesis is rejected for DGAGLOM. This means that the variables that do not reject the null hypothesis may differ for regions with and without foreign hotels. This suggests that only PROTAREAS and AIRTEMP are not relevant to include in the logit model to explain the variable FORG_HOT15_dummy.

The summary of the logit model (eq. 2), presented in table 4, indicates that only a few variables suggested by the explanatory analysis are significant for the model: IMPORT, HISTCULT, BATHWATER and AIRTEMP.

Table 4: Summary of logit model in Equation 2

\begin{tabular}{|c|c|c|c|c|c|}
\hline $\begin{array}{c}\text { Independent } \\
\text { Variables }\end{array}$ & Estimate & Std. Error & $z$ value & $p$-value & $\exp ($ beta_i) \\
\hline (INTERCEPT) & $-3.567 e+00$ & $4.017 e-01$ & -8.880 & 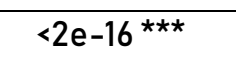 & 0.03 \\
\hline EXPORT & $-3.722 e-02$ & $4.281 e-02$ & -0.869 & 0.3847 & 0.96 \\
\hline IMPORT & $1.031 e-01$ & $5.363 e-02$ & 1.923 & 0.0545 * & 1.11 \\
\hline DGAGLOM & $-8.343 e-05$ & $1.730 e-03$ & -0.048 & 0.9615 & 1.00 \\
\hline GRAD & $-9.761 e-02$ & $1.516 \mathrm{e}-01$ & -0.644 & 0.5196 & 0.91 \\
\hline MASTR & $-6.852 e-02$ & $2.716 \mathrm{e}-01$ & -0.252 & 0.8008 & 0.93 \\
\hline PhD & $2.531 e+01$ & $2.630+03$ & 0.010 & 0.9923 & 98173288097,15 \\
\hline PROFC & $-3.256 e-03$ & $6.130 \mathrm{e}-02$ & -0.053 & 0.9576 & 1.00 \\
\hline HISTCULT & $2.667 e-01$ & $5.296 e-02$ & 5.037 & $4.74 \mathrm{e}-07^{\star \star \star}$ & 1.31 \\
\hline PROTAREAS & $1.150 e-01$ & $3.471 e-01$ & 0.331 & 0.7404 & 1.12 \\
\hline BATHWATER & $2.593 e-01$ & $5.865 e-02$ & 4.421 & $9.84 e-06$ *** & 1.30 \\
\hline AIRTEMP & $-2.626 e-03$ & $1.258 e-03$ & -2.088 & 0.0368 * & 1.00 \\
\hline Null deviance & \multicolumn{5}{|c|}{279.68 on 307 degrees of freedom } \\
\hline Residual deviance & \multicolumn{5}{|c|}{169.35 on 296 degrees of freedom } \\
\hline AIC & \multicolumn{5}{|c|}{193.35} \\
\hline
\end{tabular}


The Hosmer-Lemeshow statistical test is $X^{2}=4.2784$, with 8 degrees of freedom and a $p$-value of 0.8312 . For a significance level of 0.05 the null hypothesis is not rejected, thus the model is correctly adjusted to the data. In turn, the likelihood ratio test presents a $p$-value of 0.39 , with 12 degrees of freedom.

The mean of Pearson's residuals is near zero $(0.0066)$ and the variance is small $(0.9772)$, showing that the model is valid.

Figure 2 indicates that some outliers are present for the deviance residuals, but only 11 observations have a residual deviance greater than 2. As most of the residues are between -2 and 2 , the model proves to be adjusted.

Fig 2: Fitted values and index $x$ residual deviance
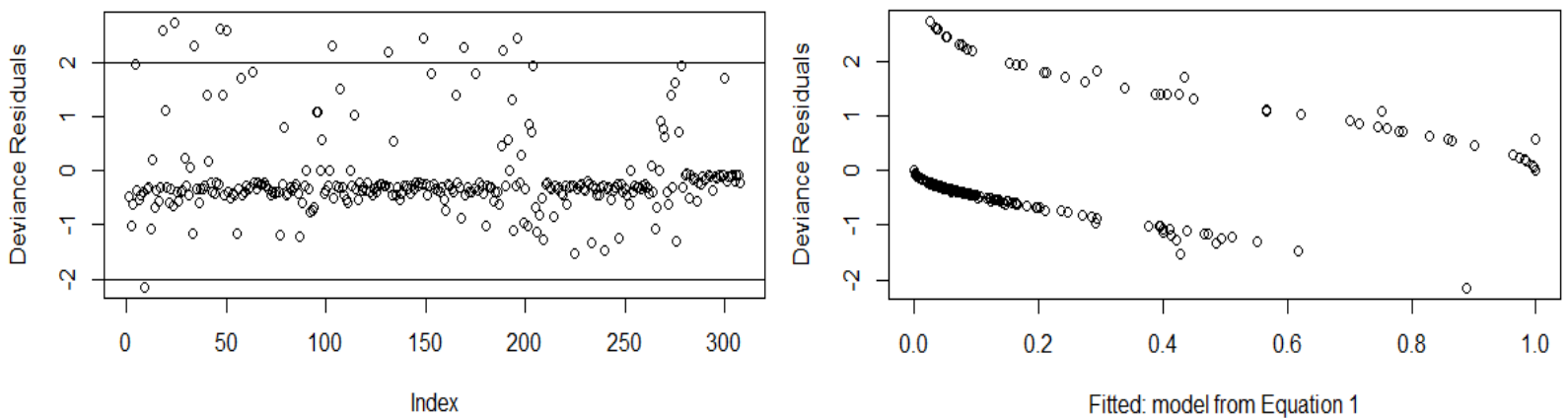

\subsection{Discussion}

In order to survive in the weak market of opportunities, companies tend to exploit their advantages in foreign markets, and thus they seek to internationalize. According to the flows of foreign investment, the hospitality sector is considered the most internationalized industry, with investment being an important factor for attracting tourists (Dwyer et al., 1994). Taking businesses outside the national territory has as main objective obtaining profit in the long term (Ayazlar, 2015). In the hotel industry, FDI can take many forms, such as building new hotels, expanding pre-existing hotels, fusions and acquisitions, or joint ventures (Falk, 2016), but entry mode varies according to the characteristics of the destination country.

The exploitation of internal advantages in new markets allows hotel companies to reduce unit costs by transferring resources, human capital and technology between the main establishment and the divisions, creating a global space for integration (Go et al., 1995). In turn, for investment in hotels in different countries, management needs to be aware of consumer preferences and cultural values (Yarcan, 1998).

The OLI paradigm, previously applied by several researchers (0'Gorman et al., 2000; Stoian et al., 2008; Assaf et al., 2015) to the hospitality industry, as an explanatory theory of internationalization (Johnson et al., 2005), allows to identify activities or resources that create added value for the hotel industry, in new markets and to identify competitive advantages of hotels in deciding where and how to internationalize. 
There are three conditions for the internationalization of hotel enterprises, one related to tangible and intangible resources, which is the biggest advantage against competition. Ownership advantage can mitigate negative conditions in entering new markets, such as the lack of information and other costs, through brand image, technology and qualified human resources (Konig, 2003). In this sense, as the product sold by the hotel sector cannot be tried before the purchase, the reputation of the touristic agent or the brand of the hotel chain aids as a guarantee of quality of the product offered (Buckley et al., 1996).

Another factor that conditions internationalization is the physical conditions of the destination compared to the country of origin, and better conditions are reflected in the increase of profitable opportunities and the reduction of costs. This can be considered an external factor to the business that can be explained by the economic, social, cultural and political characteristics of the country of destination (Kantarci, 2007).

Finally, the advantage of internalization indicates the most cost-effective decision between investment or licensing. This explains why firms prefer to internalize value-added activities rather than delegating these advantages to foreign investors (Dunning et al., 2007). Thus, in order to monetize the activity, hotel chains can transfer their property advantages, i.e. their organizational structure, to a new market (Dunning, 1988).

Although inward and outward Foreign Direct Investment (FDI) are not accounted in imports and exports, it is interesting to verify that inward FDI is associated to imports and outward FDI with exports. This seems to suggest that some regions are 'receivers' while others are 'senders'. Further research may also explore the differences between these two types of regions. Although one would expect that history, culture and bathwaters determine foreign hotels to locate in a given region, it is not as obvious that it impacts on the probability of locally owned hotels internationalize. One may claim that such conditions have allowed locally owned hotels to grow and to develop to a level that they had searched for international markets, in order to exploit their historically accumulated skills and knowledge.

Although training and education in the hotel industry does not seem to increase the probability of a region to receive international hotel chains, it improves the probability of local hotels to enter in international markets. However, it is not clear that this relationship operates in a single direction only. One may also be led to conclude that the creation and development of courses for the hospitality industry is a consequence of the existence of locally owned internationalized hotels. The exploration of such relationship requires further research and one suggests structural equation modelling to further explore it.

Considering OLI paradigm, the internationalisation occurs when hotels have ownership, location and internalization advantages. In this sense the hotel industry prefers to internationalize when they have more qualified human resources and better market conditions than international competition, while foreign hotels do not search regions with skilled labour, because intellectual capacities and knowledge are at the basis of the decision to entry in external markets. 
Another important factor in the hotels' internationalisation decision are the touristic resources of each region, since these are responsible to attract tourist. That way, hotels tend to internationalize when they have historical-cultural resources, protected areas and bathwaters, while foreign hotels prefer regions with specific conditions and high demand, i.e. locations with warmer weather, beaches and historical-cultural attractions.

To minimize risks and dependency, the internationalized hotels search to internalizes assets, in this case, the knowledge resources before entry in different markets.

\section{Conclusion}

In recent years, tourism has been recognized as an important mechanism for the development of regions, providing long-term benefits. The different cultures and touristic resources of each Portuguese region explain the location of the hotels (Rodríguez, 2002), based on favourable conditions for the activity. Therefore, the complex network of direct and indirect interactions between complementary economic activities (Assaf et al., 2012) generate positive tourism flows allowing a sustainable development and internationalisation of the economy, and attraction of foreign investment (Barros, et al., 2011; Chen, 2010).

Through the logistic regression model for the internationalisation of the hotels, it was possible to verify that the local imports and exports contribute to the probability of hotels to internationalize. Thus, regions presenting more imports and exports tend to have a greater number of internationalized hotels. On the other hand, the model for attracting foreign hotels indicates that only imports contribute to the establishment of multinational hotels, with the transfer of a hotel service from a foreign country to the domestic market. This factor indicates that the location of hotels in counties with higher international transactions contributes to the internationalization, since hospitality sector is attracted by the competitiveness generated by the opportunities, searching new markets for their services or transferring the service from the country of origin to the country of destination (Alon, et al., 2013; Sozuer, et al., 2017).

As far as agglomeration is concerned, it would be expected to contribute to the internationalisation and attraction of foreign hotel chains due to the existence of positive externalities underlying clusters. However, it is not verified that a county has more internationalized or foreign hotels because of the benefits associated with the concentration of complementary tourist activities. This indicator can be explained by the existence of different typologies in the hotel industry, which target different markets, so they have different location strategies. (Li et al., 2015). In turn, the more experienced or larger hotel chains, in general, have competitive advantages in the domestic market that can transfer to the potential market, a decision that may have an impact on the choice of location (Luo et al., 2016).

In terms of training, it has been shown that the availability of a greater number of courses and investment in higher education, specialized and specific to the sector impacts on the probability hotels to internationalize. In the tourism sector, hotel chains tend to expand to external countries 
only when they have accumulated knowledge and experience, thus avoiding risks and uncertainties associated with the process. In turn, the establishment of foreign hotel chains in a county is not determined by the existence of specific training in the region, as these develop their internal organizational capacities based on existing knowledge resources. Thus, qualified employees are important for the hotel sector, since the knowledge, experience and know-how are intrinsic characteristics of human resources, and the existence of training directed to the hospitality sector represents an advantage (Sanoner, 2015). However, learning can also be managed internally through the management of the hotel chain.

Finally, natural and historical-cultural tourism resources contribute to the probability of a county to have internationalized or foreign hotels, as tourism demand is essentially based on the opportunity to explore and discover touristic attractions in the destination county. Still associated with touristic resources, foreign hotels seek to settle in countries where temperatures are more favourable since this variable influences the decisions of tourists. In this sense, the experience of tourists is influenced by multiple factors, namely by tourism firms, i.e. hotels, restaurants and transportation infrastructures, and by complementary services, i.e. museums, leisure activities and commerce (Crouch, 2010). Thus, the location of hotels in destinations with a network of suppliers and contacts allows the increase of quality in the services provided to the tourist and the consequent reduction of costs (Sanoner, 2015).

In summary, international commercial transactions, specialized knowledge and tourist resources in a county contribute to the probability of these regions to have internationalized hotels or to receive foreign hotels. Within the variables under study, only agglomeration and the lowest levels of education are not statistically significant for the probability of internationalisation and foreign investment in the hotel industry.

The literature and the study provide for companies in the hospitality sector information that allows the decision to choose the market to be exploited, considering location factors. These provide guidance on the choice of international destinations and on the acquisition or development of resources, i.e. experience, brand quality and knowledge (Assaf et al., 2015). Given that hospitality is a labour-intensive industry, it can be beneficial to entrepreneurs in the tourism industry in order to improve their competitiveness and performance globally, hire qualified human resources and continuously invest in internal training, as an advantage of internalisation and ownership (Tayeb, 1995), which allows the provision of quality products/ services to clients and the optimization of hotel management.

During the research process some limitations were identified, namely related to the lack or omission of certain data that may influence the results, so it would be interesting to refine the model in the future by reclassifying the resources present in each category, as well as to consider conducting a temporal analysis covering more years, to compare results and the evolution of the Portuguese hospitality.

Our study has approached the hotel industry. However, the tourism industry includes firms of different nature than just the hotels. An analysis to the tourism filiére would require a different 
dataset. Therefore, our results are valid for the hotel sector, rather than for the tourism industry. These study raises opportunities to explore the different forms of internationalisation of tourism firms (that are not hotel chains), and the extent to which these firms face the same of different obstacles to enter international entry.

In addition, within the hotel industry, the literature refers to the existence of strategic groups and one needs to acknowledge that hotels may vary in terms of their market positioning, nature and size. One may claim that the different hotel types may engage into different forms of internationalisation. Further research may explore how different hotel types adopt different forms of international markets entry.

\section{References}

Alon, I. (2004). International Market Selection For A Small Enterprise: A Case Study In International Entrepreneurship. SAM Advanced Management Journal, 69 (1), 25-33.

Alon, I., Ni, L., \& Wang, Y. (2012). Examining The Determinants Of Hotel Chain Expansion Through International Franchising. International Journal of Hospitality Management 31, 379-386.

Alon, I., Yeheskel, 0., Lerner, M., \& Zhang, W. (2013). Internationalisation of Chinese Entrepreneurial Firms. Thunderbird International Business Review, 55, 5, 495-512.

Assaf, A. G., \& Josiassen, A. (2012). Identifying and Ranking the Determinants of Tourism Performance a Global Investigation. Journal of Travel Research 51, 388-399.

Assaf, A. G., Josiassen, A., \& Agbola, F. W. (2015). Attracting International Hotels: Locational Factors That Matter Most. Tourism Management 47, 329-340.

Asiedu, E. (2006). Foreign Direct Investment in Africa: The Role of Natural Resources, Market Size, Government Policy, Institutions and Political Instability. The World Economy 29, 63-77.

Autio, E., Sapienza, H., \& Almeida, J. (2000). Effects Of The Age At Entry, Knowledge Intensity, And Imitability On International Growth. Academy of Management Journal, 41, 909-924.

Ayazlar, G. (2015). Internationalization of the Lodging Industry in the Light of Eclectic Paradigm. Procedia Economics and Finance 26, 875-882.

Barber, J. P., León-Darder, F., \& Villar, C. (2011). The Internationalization of Soft-Services: Entry Modes and Main Determinants in the Spanish Hotel Industry. Service Business 5, 139-154.

Barros, C. P., Botti, L., Peypoch, N., Robinot, E., B. S., \& Assaf, A. G. (2011). Performance of French Destinations: Tourism Attraction Perspectives. Tourism Management 32, 141-146.

Brida, J. G., Driha, O. M., Ramón-Rodríguez, A. B., \& Scuderi, R. (2015). Dynamics of Internationalisation of the Hotel Industry: The case of Spain. International Journal of Contemporary Hospitality Management 27, 1024-1047.

Bozkurt, K., Guler, N., \& Bahar, O. (2018). Fuzzy Convergence In Tourism Economics. Jounal of Tourism Theory and Research 4(1), 1-15.

Buckley, P. J., \& Geyikdagi, N. V. (1996). Explaining Foreign Direct Investment in Turkey's Tourism Industry. The Nature od the Firm, Economia 4, 386-405. 
Burger, M. J., Karreman, B., \& Eenennaam, F. v. (2015). The Competitive Advantage of Clusters: Cluster Organisations and Greenfield FDI in the European Life Sciences Industry. Geoforum 65. 179-191.

Burger, M. J., Knaap, B. v., \& Wall, R. S. (2013). Revealed Competition for Greenfield Investments Between European Regions. Journal of Economic Geography 13, 619-648.

Carrasqueira, H. (2014). Hotelaria Internacional. Universidade Algarve, 1-54.

Chaisumpunsakul, W., \& Pholphirul, P. (2017). Does International Trade Promote International Tourism Demand? Evidence From Thailand's Trading Partners. Kasetsart Journal of Social Sciences, 1-8.

Chen, M.-H. (2010). The Econoy, Touris Growth and Corporate Performance in the Taiwanese Hotel Industry. Tourism Management 31,665-675.

Chen, M.-H. (2016). A quantile regression analysis of tourism market growth effect on the hotel industry. International Journal of Hospitality Management 52, 117-120.

Ciravegna, L., Kuivalainen, O., Kundu, S. K., \& Lopez, L. E. (2018). The Antecedents Of Early Internationalisation: A Configurational Perspective. International Business Review.

Clavel, M., Fernández-Ortiz, R., Arteaga-Ortiz, J., \& Valencia, H. (2017). A Resource-Based Analysis of The Internationalisation Process Of Spanish Wineries. European Journal of International Management, 11 (1), 19-41.

Cleeve, E. (2008). How Effective are Fiscal Incentives to Attract FDI to Sub-Saharan Africa? Journal of Developing Areas 42(1), 135-153.

Cocklin, C., Harte, M., \& Hay, J. (1990). Resource Assessment For Recreation And Tourism: A New Zealand Example. Landscape and Urban Planning 19, 291-303.

Cohen, W., \& Levinthal, D. (1990). Absorptive Capacity: A New Perspective On Learning And Innovation. Administrative Science Quarterly35(1), 128-152.

Crouch, G. I. (2010). Destination Competitiveness: An Analysis of Determinant Attributes. Journal of Travel Research 50, 27-45.

Deloitte. (2018). Unlimited Expectations. Atlas da Hotelaria 2018 - 13ª Edição, pp. 1-28.

Dunning, J. H. (1988). The eclectic paradigm of international production: a restatement and some possible extensions. Journal of International Business Studies 19, 1-31.

Dunning, J. H., Pak, Y. S., \& Beldona, S. (2007). Foreign Ownership Strategies of UK and US International Franchisors: An Exploratory Application of Dunning's Envelope Paradigm. International Business Review 16, 531-548.

Dwyer, L., \& Forsyth, P. (1994). Foreign Tourism Investment: Motivation and Impact. Annals of Tourism Research 21, 512-537.

Falk, M. (2016). A Gravity Model of Foreign Direct Investment in the Hospitality Industry. Tourism Management 55, 225-237.

Ferraris, A., Santoro, G., \& Bresciani, S. (2017). Open Innovation In Multinational Companies' Subsidiaries: The Role Of Internal And External Knowledge. European Journal of International Management, Vol. 11, No.4, 452-468. 
Franco, M., \& Haase, H. (2016). Internationalisation of Born Globals: The Role of Strategic Alliances. European Journal of International Management, 10 (2), 181-201.

Game, R., \& Apfelthaler, G. (2016). Attitude And Its Role In SME Internationalisation: Why Do Firms Commit To Advanced Foreign Market Entry Modes? European Journal of International Management, Vol.10, No.2, 221-248.

Garin-Munoz, T., \& Amaral, T. P. (2000). An Econometric Model For International Tourism Flows To Spain. Applied Economics Letters (7), 525-529.

Go, F. M., \& Pine, R. (1995). Globalization Strategy in the Hotel Industry. London: Routledge.

Grant, R. M. (2010). Contemporary Strategy Analysis and Cases: Text \& Cases. International Journal of Management Education 8, 1-944.

Hsu, S. T.-H., Iriyama, A., \& Prescott, J. E. (2016). Lost in Translation or Lost in Your Neighbor's Yard: The Moderating Role of Leverage and Protection Mechanisms for the MNC Subsidiary Technology Sourcing-Performance Relationship. Journal of International Management 15(2), 8499.

Hummelbrunner, R., \& Miglbauer, E. (1994). Tourism Promotion and Potential in Peripheral Areas: The Austrian Case. Journal of Sustainable Tourism 2, 41-50.

Johanson, J., \& Vahlne, J. (1977). The Internationalisation Process Of The Firm: A Model of Knowledge And Increasing Foreign Commitments. Journal of International Business Studies 8. 23-32.

Johnson, C., \& Vanetti, M. (2005). Market Developments in the Hotel Sector in Eastern Central Europe. Advances in Hospitality and Leisure 1, 153-175.

Kamakura, A. W., Ramón-Jerónimo, A. M., \& Gravel, J. D. (2012). A Dynamic Perspective To The Internationalisation Of Small-Medium Enterprises. Journal of the Academy of Marketing Science 40, 236-251.

Kantarci, K. (2003). Perceptions of Foreign Investors on the Tourism Market in Central Asia Including Kyrgyzstan, Kazakhstan, Uzbekistan, Turkmrnistan. Tourism Management, 820-829.

Knight, G. A., \& Cavusgil, S. T. (2004). Innovation, Organizational Capabilities, And The BornGlobal Firm. Journal of International Business Studies, 35, 124-141.

Konig. M. (2003). An Econometric Framework for Testing the Eclectic Paradigm of International Firms Activities. Reviw of World Economics 139, 484-506.

Kottaridi, C., \& Lioukas, S. (2017). Firm Competencies And Exports Among SMEs: The Critical Role Of Collaborations. European Journal of International Management, Vol. 11, No. 6, 711-732.

Kraus, S., Niemand, T., Besler, M., Stieg, P., \& Martinez-Ciment, C. (2018). The Influence of Leadership Styles On The Internationalisation Of 'Born-Global' Firms And Traditionally GlobalExpanding Firms. European Journal of International Management, Vol. 12, No. 5/6, 554-575.

Lattemann, C., \& Alon, I. (2015). The Rise of Chinese Multinationals: A Strategic Threat Or An Economic Opportunity? Georgetown Journal of International Affairs, 16 (1), 172-179.

Li, M., Fang, L., Huang, X., \& Goh, C. (2015). A Spacial-Temporal Analysis of Hotels in Urban Tourism Destination. International Journal of Hospitality Management 45, 34-43. 
Luo, H., \& Yang, Y. (2016). Intra-Metropolitan Location Choice of Star-Rated and Non-Rated Budget Hotels: The Role of Agglomeration Economies. International Journal of Hospitality Management 59, 72-83.

Lyons, S., Mayor, K., \& Tol, R. S. (2009). Holiday Destinations: Understanding The Travel Choices Of Irish Tourists. Tourism Management 30, 683-692.

Mahmoodi, M. (2016). Foreign Direct Investment, Exports And Economic Growth: Evidence From Two Panels Of Developing Countries. Economic Research 29, 938-949.

Majocchi, A., Odorici, V., \& Presutti, M. (2016). Firm Ownership And Internationalisation: Is It Context That Really Matters? European Journal of International Management, Vol. 10, No.2, $202-$ 220.

Marco-Lajara, B., Claver-Cortés, E., Úbeda-García, M., \& Zaragoza-Sáez, P. D. (2016). Hotel Performance and Agglomeration of Tourist Districts. Regional Studies 50, 1016-1035.

Marco-Lajara, B., Zaragoza-Sáez, P. d., Claver-Cortés, E., Úbeda-García, M., \& García-Lillo, F. (2017). Tourist Districts And Internationalisation Of Hotel Firms. Tourism Management 61 , 451 e464.

Matthews, A. J., \& Zander, I. (2007). The International Entrepreneurial Dynamics of Acelerated Internationalisation. Journal of International Business Studies 38, 387-403.

McDougall, P., \& Oviatt, B. (2000). International Entrepreneuship: The Intersection Of Two Research Paths. Academy of Management Journal, 43, 902-906.

Mohamed, E. S., \& Sidiropoulos, G. M. (2010). Another Look at the Determinants of Foreign Direct Investment in MENA Countries: An Empirical Investigation. Journal of Economic Development 35(2), 75-95.

Moneris. (2017). Análise Hoteleira Anuário 2017. Centro de Competências do Turismo, pp. 1-36.

Morschett, D., Schramm-Klein, H., \& Swoboda, B. (2010). Decades of Research on Market Entry Modes: What Do We Really Know About External Antecedents of Entry Mode Choice? Journal of International Management 16,60-77.

Nakos, G., \& Brouthers, K. D. (2002). Entry Mode Choice of SMEs in Central and Eastern Europe. Entrepreneurship Theory and Practice 26, 47-63.

Oliveira, A., Braga, V., \& Silva, E. C. (2019). Internationalisation Strategies For Tourism In Portugal. Innovation, Engineering and Entrepreneurship. HELIX 2018. Lecture Notes In Electrical Engineering, vol 505. Springer, Cham, 978-984.

O'Gorman, C., \& McTiernan, L. (2000). Factor Influencing the Internationalization Choices of Small and Medium-Sized Enterprises: The Case of the Irish Hotel Industry. Enterprise and Innovation Management Studies 1, 141-151.

Oyna, S., \& Alon, I. (2018). A Review of Born Globals. International Studies of Management \& Organization, 157-180.

Papadopoulos, N., \& Martín, 0. M. (2010). Toward a Model of the Relationship Between Internationalisation and Export Performance. International Business Review 19, 388-406. 
Peters, M., \& Frehse, J. (2005). The Internationalization of the European Hotel Industry in the Light of Competition Theories. Tourism 53, 55-65.

Phelps, N. A. (2008). Cluster or Capture? Manufacturing Foreign Direct Investment, External Economies and Agglomeration. Regional Studies 42, 457-473.

Propis, L. D., \& Driffield, N. (2006). The Importance of Clusters For Spillovers From Foreign Direct Investment and Tecnology Sourcing. Cambridge Journal of Economics 30, 277-291.

Rendón, O. H., Martínez, R. M., \& Ramírez-Flores, M. S. (2014). Marketing Strategies for Hotel Industry Internationalization in Morelia. Procedia - Social and Behavioral Sciences 148, 271-279.

Rodríguez, A. R. (2002). Determining Factors In Entry Choice For International Expansion. The Case Of The Spanish Hotel Industry. Tourism Management 23, 597-607.

Rodríguez, A. X., \& Rivadulla, R. (2012). Tourism In Spain: Disaggregated Analysis Of The International Demand. Regional and Sectoral Economic Studies 12-1, 77-82.

Rodríguez-Clare, A. (2007). Clusters and Comparative Advantage: Implications for Industrial Policy. Journal of Development Economics 82, 43-57.

Sanoner, F. (2015). The Internationalisation of Small and Medium Enterprises in the Hotel Industry: The Case Adler Spa Resorts. Cand. Merc. Program International Marketing and Management, 1-122.

Solvell, O., Lindqvist, G., \& Ketels, C. (2003). The Cluster Initiative Greenbook. Stockholm School of Economics, 1750-1848.

Soriano, D. R., Palacios-Marqués, D., Devece-Carañana, C., \& Peris-Ortíz, M. (2014). How To Create International Business Competences And Their Impact On Firm Performance. European Journal Of International Management, Vol. 8, No. 3, 279-292.

Sozuer, A., Altuntas, G., \& Semercioz, F. (2017). International Entrepreneurship Of Small Firms And Their Export Market Performance. European Journal of International Management, Vol. 11, No.3,365-382.

Stoian, C. R., \& Filippaios, F. (2008). Dunning's Eclectic Paradig: A Holistic, Yet Context Specific Framework for Analysing the Determinants of Outward FDI: Evidence from International Greek Investments. International Business Review 17, 349-367.

Tayeb, M. (1995). The Competitive Advantage of Natitons: The role of HRM and its Socio-Cultural Context. The International Journal of Human Resource Management 6, 588-605.

Theodorakopoulos, N., Patel, C., \& Budhwar, P. (2012). Editorial: Knowledge Flows, Learning And Development In An International Context. European Journal of International Management, Vol. 6, No. 1,1-9.

Tomás-Miquel, J.-V., Expósito-Langa, M., Belso-Martínez, J.-A., \& Mas-Verdú, F. (2018). Multinational Enterprise Subsidiaries In Local Clusters: Embeddedness Or Isolation? European Journal of International Management, Vol.12, No.5/6, 624-641.

Tuppura, A., Saarenketo, S., Puumalainen, K., Jantunen, A., \& Kylaheiko, K. (2008). Linking Knowledge, Entry Timing And Internationalisation Strategy. International Business Review 17. 473-487. 
Vijayakumar, N., Sridharan, P., \& Rao, S. (2010). Determinants of FDI in BRICS Countries: A panel Analysis. Business Science \& Applied Management 5, 1-13.

Wakefield, C. \&. (29 de Novembro de 2017). Portugal Hotelaria. Mercado Hoteleiro 2017, pp. 128.

Wang, S. Q., Dulaimi, M. F., \& Aguria, M. Y. (2004). Risk Management Framework for Construction Projects in Developing Countries. Construction Management and Economics 22, 237-252.

Wong, J., Newton, J. D., \& Newton, F. J. (2014). Effects Of Power And Individual-Level Cultural Orientation On Preferences For Volunteer Tourism. Tourism Management 42, 132-140.

Yang, Z., \& Cai, J. (2016). Do Regional Factors Matter? Determinants Of Hotel Industry Performance In China. Tourism Management 52, 242-253.

Yarcan. (1998). The Routledge Handbook of Hotel Chain Management. London: Routledge.

Zahra, A. S., Korri, J. S., \& Yu, J. (2005). Cognition And International Entrepreneurship: Implications For Research On International Opportunity Recognition And Exploitation. International Business Review 14(2), 129-146. 


\section{Chapter V}

\section{Conclusions}




\section{Main Conclusions}

Recognized as a sector of activity responsible for a large number of services exports, the intensity of labour, the large number of connections with other industries and the spillover effect between producers and consumers, the tourism industry has represented, for Portugal, the main source of employment and capital, with a positive relationship with economic growth and the natural and cultural value of the regions. (Brida et al., 2014)

Considering the above points and the proposed objectives for research, several conclusions can be highlighted, namely:

- In the first article "Internationalization Strategies from Tourism in Portugal", through the analysis of multivariate linear regression, it was verified that the location in territories possessing favourable conditions for the activity, i.e., in locations with greater concentration of firms related to the sector, is statistically significant for the internationalization of hotel chains. Cluster membership enables tourism businesses to meet their resource needs and effectively collaborate to achieve common goals, as well as to reduce the costs and risks associated with implementing innovation in products / services and entering in new markets.

Despite the importance attributed to the knowledge and qualification of human resources required by the labour force, the study revealed that not all specialized knowledge variables are statistically significant for the internationalization decision. These indicate that the hotel industry values, essentially, the establishment of connections with firms in the activity segment, to gain competitive advantages and thus acquire knowledge and experience for the internationalization process, not needing to look for specialized labour in the market.

In turn, in terms of touristic resources, i.e. natural, historical-cultural and capital, the study shows that only the natural heritage is statistically significant for hotel internationalization. In this way, firms benefit from local factors, which influence their ability to exploit these specific resources and internationalize by having competitive advantages in the domestic market.

- The second article, "Internationalization Innovative Strategies for Tourism in Portugal: Municipal Analysis and International Tourists", partly similar to the first and using the same analysis technique, but at the level of the counties, also revealed that the agglomeration, as well as some resources of knowledge are statistically significant for the internationalization of hotels, confirming that the combination of the advantages acquired within the clusters and the capacities generated through educational institutions allow to identify and exploit opportunities in external markets.

Also, in this article, the introduction of a new dependent variable, i.e., proportion of international tourists, allowed us to conclude that the agglomeration is statistically significant. In this sense, international tourists seek locations that offer greater benefits, such as the proximity of services, infrastructure complementary to accommodation and built and immaterial heritage. 
It was also verified that the knowledge generated by university institutions and professional education contribute to attracting and retaining international tourists, since more qualified services, with a greater diffusion of specific knowledge, with an increase of innovation and more creative strategies, give tourists a social experience, meet their needs to feel "part of a culture" and their interests. Through the maps it was also possible to characterize the counties and verify the distribution of the variables under study.

- Finally, in the third article "When Hotels Go Abroad: The Internationalization of the Portuguese Hospitality", contrary to what was expected, since in the previous studies the agglomeration had an important role in the decision of internationalization, it was verified through the logistic regression model that the concentration of firms related to the sector does not contribute to the probability of hotels internationalizing, i.e., it is not verified that, in a given county, there is a greater number of hotels internationalized due to the benefits inherent in the degree of agglomeration of firms in the tourism segment. Likewise, there is no likelihood that foreign hotels will settle in certain counties that are driven by a greater degree of agglomeration, so that foreign hotels internally have competitive advantages, skills and resources that allow them to enter new markets without the need to settle with clusters.

In terms of knowledge resources, there is evidence that the existence of a greater educational offer and the investment in higher education, specialized and specific to the sector of activity in the county, contributes to the probability of the hotel chains to internationalize. In general, firms tend to accumulate and acquire knowledge internally and through the establishment of links with other organizations, in order to gain know-how and experience, to incorporate quality and innovation in the services offered and a more sustainable and uncertainties in foreign markets. On the other hand, specific training does not contribute to the probability of establishing foreign hotels in a county, since these have internal knowledge and organizational capacities that can be developed and improved without the need to search externally specific knowledge.

About tourist resources, these have been gaining a growing contribution in the segment to the probability of internationalization and attraction of foreign investment. In this sense, counties with the greatest natural and historical-cultural resources, respond to the needs of tourist demand, are more attractive to hotel multinationals and provide advantages to national hotels that aim to internationalize.

The macroeconomic variables analysed in the study, i.e., import and export, indicate that the location of hotels in counties with higher transactions contributes to the probabilities of internationalization, since they are attracted by the competitiveness generated by the opportunities, searching new markets for their services. In the case of foreign hotels, only imports contribute to the probability that they will establish in a certain county, transferring the service from the country of origin to the country of destination. 
Finally, weather conditions, i.e. temperature, contribute to the attraction of hotel multinationals to counties, since the climate can influence the decision of tourists affecting the demand and the offer of services.

In summary, agglomeration is an important factor in the internationalization of hotel chains, as well as knowledge and touristic resources, which have gained a significant importance with the need to incorporate innovation and differentiation in the touristic offer. Macroeconomic factors have also contributed to the incentive to exploit new opportunities in foreign markets. Regarding foreign direct investment, this is mainly motivated by the tourist resources of a region, since the multinational has advantages and knowledge internally, being willing to enter in new markets to exploit location advantages. It is also noted that the proportion of international tourists that a country captures annually is justified by the levels of knowledge, tourism firms and complementary infrastructure available in the regions.

\section{Limitations and Future Research}

During the research process some limitations were identified. In the first article, the size of the sample was identified as a major limitation, which may have skewed the results. In terms of comparison with the study by Marco-Lajara et al., (2017) for the Spanish territory, there were several discrepancies in the results that may be related not only to the size of the sample, but also to factors inherent to the geography, population, employment and infrastructures of each Portuguese TU. Still in terms of limitations, the lack or omission of certain data may have influenced the results, so it would be interesting to refine the model in the future by reclassifying the resources present in each category.

In this sense, in the second and third article the sample was expanded, eliminating the main limitation of the first article.

Our study has approached the hotel industry. However, the tourism industry includes firms of different nature than just the hotels. An analysis to the tourism filiére would require a different dataset. Therefore our results are valid for the hotel sector, rather than for the tourism industry. These study raises opportunities to explore the different forms of internationalisation of tourism firms (that are not hotel chains), and the extent to which these firms face the same of different obstacles to enter international entry.

In addition, within the hotel industry, the literature refers to the existence of strategic groups and one needs to acknowledge that hotels may vary in terms of their market positioning, nature and size. One may claim that the different hotel types may engage into different forms of internationalisation. Further research may explore how different hotel types adopt different forms of international markets entry. 


\section{References}

Brida, J. G., Londres, S., \& Rojas, M. (2014). El turismo como fuente de crecimiento económico: impacto de las preferencias intertemporales de los agentes. Pesquisa Econômica 73, 59-77.

Marco-Lajara, B., Zaragoza-Sáez, P. d., Claver-Cortés, E., Úbeda-García, M., \& García-Lillo, F. (2017). Tourist Districts And Internationalization Of Hotel Firms. Tourism Management 61, 451-464. 